\title{
Sensitivity analysis of the effect of wind characteristics and turbine properties on wind turbine loads
}

\author{
Amy N. Robertson, Kelsey Shaler, Latha Sethuraman, and Jason Jonkman \\ National Renewable Energy Laboratory, 15013 Denver West Parkway, Golden, CO 80401, USA \\ Correspondence: Amy N. Robertson (amy.robertson@nrel.gov) \\ Received: 8 January 2019 - Discussion started: 4 February 2019 \\ Revised: 15 April 2019 - Accepted: 25 June 2019 - Published: 10 September 2019
}

\begin{abstract}
Proper wind turbine design relies on the ability to accurately predict ultimate and fatigue loads of turbines. The load analysis process requires precise knowledge of the expected wind-inflow conditions as well as turbine structural and aerodynamic properties. However, uncertainty in most parameters is inevitable. It is therefore important to understand the impact such uncertainties have on the resulting loads. The goal of this work is to assess which input parameters have the greatest influence on turbine power, fatigue loads, and ultimate loads during normal turbine operation. An elementary effects sensitivity analysis is performed to identify the most sensitive parameters. Separate case studies are performed on (1) wind-inflow conditions and (2) turbine structural and aerodynamic properties, both cases using the National Renewable Energy Laboratory 5 MW baseline wind turbine. The Veers model was used to generate synthetic International Electrotechnical Commission (IEC) Kaimal turbulence spectrum inflow. The focus is on individual parameter sensitivity, though interactions between parameters are considered.

The results of this work show that for wind-inflow conditions, turbulence in the primary wind direction and shear are the most sensitive parameters for turbine loads, which is expected. Secondary parameters of importance are identified as veer, $u$-direction integral length, and $u$ components of the IEC coherence model, as well as the exponent. For the turbine properties, the most sensitive parameters are yaw misalignment and outboard lift coefficient distribution; secondary parameters of importance are inboard lift distribution, blade-twist distribution, and blade mass imbalance. This information can be used to help establish uncertainty bars around the predictions of engineering models during validation efforts, and provide insight to probabilistic design methods and sitesuitability analyses.
\end{abstract}

Copyright statement. The U.S. Government retains and the publisher, by accepting the article for publication, acknowledges that the U.S. Government retains a nonexclusive, paid-up, irrevocable, worldwide license to publish or reproduce the published form of this work, or allow others to do so, for U.S. Government purposes.

\section{Introduction}

Wind turbines are designed using the International Electrotechnical Commission (IEC) 61400-1 standard (IEC, 2005), which prescribes a set of simulations to ascertain the ultimate and fatigue loads that the turbine could encounter under a variety of environmental and operational conditions. The standard applies safety margins to account for the un- certainty in the process, which comes from the procedure used to calculate the loads (involving only a small fraction of the entire lifetime), but also from uncertainty in the properties of the system, variations in the conditions the turbine will encounter from the prescribed values, and modeling uncertainty. As manufacturers move to develop more advanced wind technology, optimize designs further, and reduce the cost of wind turbines, it is important to better understand how uncertainties impact modeling predictions and reduce the uncertainties where possible. Knowledge of where the uncertainties stem from can lead to a better understanding of the cost impacts and design needs of different sites and different turbines. 
This paper provides a better understanding of the uncertainty in the ultimate and extreme structural loads and power in a wind turbine. This is done by parameterizing the uncertainty sources, prescribing a procedure to estimate the load sensitivity to each parameter, and identifying which parameters have the largest sensitivities for a conventional utilityscale wind turbine under normal operation. An elementary effects (EE) methodology was employed for estimating the sensitivity of the parameters. This approach was chosen because it provides a reasonable estimate of sensitivity, but with significantly fewer computational requirements compared to calculating the Sobol sensitivity, and does not require increasing the uncertainty in the result through the use of a reduced-order model. Some modifications were needed to the standard EE approach to properly compare loads across different wind speed bins.

This work is a first step in understanding potential design process modifications to move toward a more probabilistic approach or to inform site-suitability analyses. The results of this work can be used to (1) rank the sensitivities of different parameters, (2) help establish uncertainty bars around the predictions of engineering models during validation efforts, and (3) provide insight to probabilistic design methods and site-suitability analyses.

\section{Analysis approach}

\subsection{Overview}

To identify the most influential sources of uncertainty in the calculation of the structural loads for utility-scale wind turbines, a sensitivity analysis methodology based on EE is employed. The focus is on the sensitivity of the input parameters of wind turbine simulations (used to calculate the loads), not on the modeling software itself, which creates uncertainty based on whether the approach used accurately represents the physics of the wind loading and structural response. The procedure followed is summarized in the following subsections. The caveats of the sensitivity analysis approach employed are given as follows:

- Only the National Renewable Energy Laboratory (NREL) $5 \mathrm{MW}$ reference turbine is used to assess sensitivity (the resulting identification of most sensitive parameters may depend on the turbine).

- Only normal operation under turbulence is considered (gusts, start-ups, shutdowns, and parked or idling events are not considered).

- Minimum and maximum values of the input parameter uncertainty ranges are examined in the analysis (no joint probability density function is considered).

- With the exception of wind speed, each parameter is examined independently across the full range of variation and is not conditioned based on parameters other than wind speed.

\subsection{Wind turbine model and tools}

The sensitivity of the turbine load response to each input parameter is assessed through the use of a simulation model. The NREL 5 MW reference turbine (Jonkman et al., 2009) was used in this study as a representative turbine. This is a three-bladed upwind horizontal-axis turbine with a variablespeed collective pitch controller; it has a hub height of $90 \mathrm{~m}$ and a rotor diameter of $126 \mathrm{~m}$. Though not covered in this work, it would also be useful to examine how the sensitivity of the turbine loads to the parameters is affected by the size, type, and control of the considered wind turbine.

The sensitivity of loads to input parameter variation could be influenced by the wind speed and associated wind turbine controller response. Therefore, the EE analysis was performed at three different wind speeds corresponding to mean hub height wind speeds of 8,12 , and $18 \mathrm{~m} \mathrm{~s}^{-1}$, representing below-, near-, and above-rated wind speeds, respectively. Turbulent wind conditions were generated at each wind speed using TurbSim (Jonkman, 2009), employing an IEC Kaimal turbulence spectrum with exponential spatial coherence. Multiple turbulence seeds were used for each input parameter variation to ensure the variation from input parameter changes is distinguishable from the variation in the selected turbulence seeds. The number of seeds was determined through a convergence study for each of the parameter sets. A $25 \times 25$ point square grid of three-component wind vector points that encompasses the turbine rotor plane was used.

OpenFAST (2017), a state-of-the-art engineering-level aeroservoelastic modeling approach, was used to simulate the NREL $5 \mathrm{MW}$ wind turbine using the developed wind files, allowing for aeroelastic response and turbine operation analysis. A simulation time of $10 \mathrm{~min}$ was used after an initial $30 \mathrm{~s}$ transient period per turbulence seed. Drag on the tower was not considered because it is negligible for an operational turbine. AeroDyn, the aerodynamic module of OpenFAST, determines the impact of the turbine wake using induction factors that are computed using blade-element momentum theory with advanced corrections. Steady and unsteady aerodynamic responses were considered. Steady aerodynamic modeling uses static lift and drag curves in the momentum balance to calculate the local induction. Unsteady airfoil aerodynamic modeling accounts for dynamic stall, flow separation, and flow reattachment to calculate the local aerodynamic applied loads. ElastoDyn, a combined multibody and modal structural approach that includes geometric nonlinearities, was used to represent the flexibility of the blades, drivetrain, and tower as well as to compute structural loading, which was used to compute ultimate and fatigue loads. The baseline controller of the NREL $5 \mathrm{MW}$ turbine was enabled using ServoDyn. OpenFAST results were 


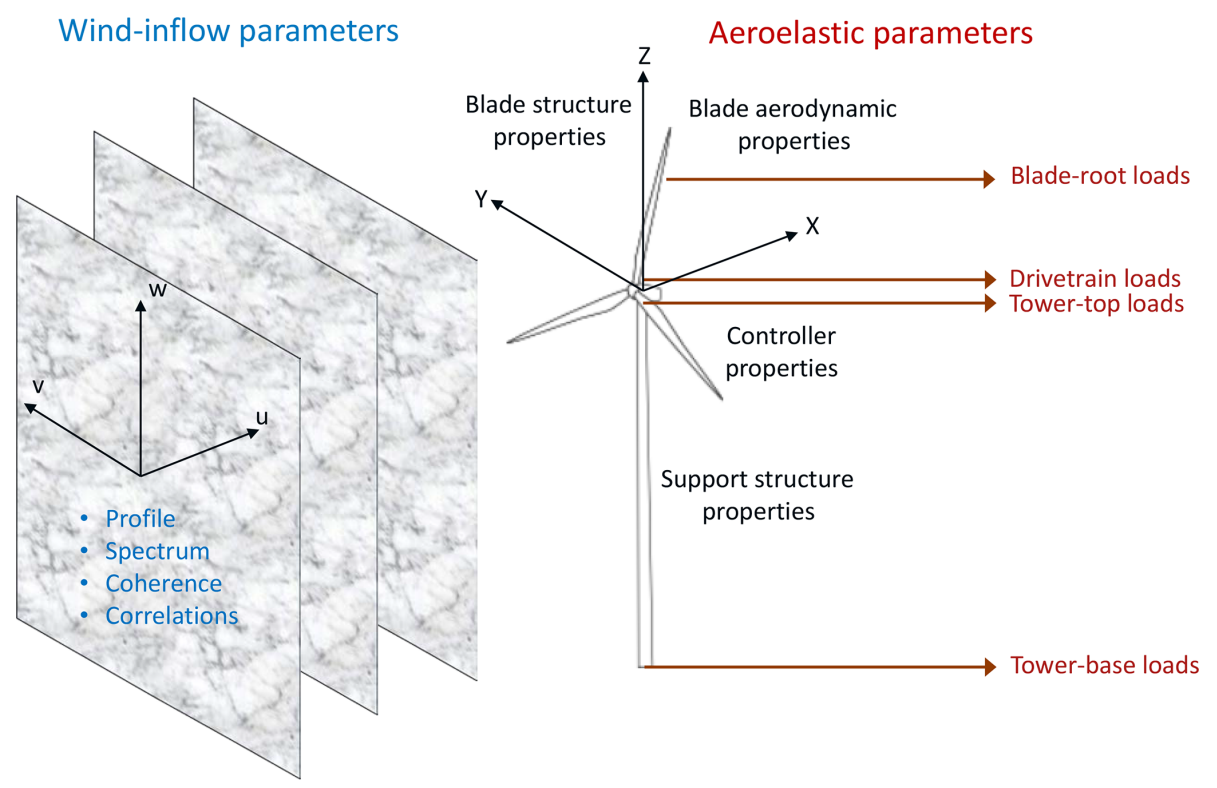

Figure 1. Overview of the parametric uncertainty in a wind turbine load analysis. Includes wind-inflow conditions (subset shown in blue), turbine aeroelastic properties (subset shown in black), and the associated load quantities of interest (QoIs) (subset shown in red).

used to assess the change in response of quantities of interest (QoIs) to changes in the physical input parameters.

\subsection{Case studies}

Input parameters were identified that could significantly influence the loading of a utility-scale wind turbine. These parameters were organized into two main categories (or case studies): the ambient wind-inflow conditions that will generate the aerodynamic loading on the wind turbine and the aeroelastic properties of the structure that will determine how the wind turbine will react to that loading (see Fig. 1). Within these two categories, a vast number of uncertainty sources can be identified, and Abdallah (2015) provides an exhaustive list of the properties. For this study, the authors selected those parameters believed to have the largest effect for normal operation for a conventional utility-scale wind turbine, which are categorized into the labels shown in Fig. 1.

To understand the sensitivity of a given parameter, a range over which that parameter may vary needed to be defined. For the wind conditions, a literature search was done to identify the reported range for each of the parameters across different potential installation sites within the three wind speed bins. For the aeroelastic properties, the parameters are varied based on an assessed level of potential uncertainty associated with each parameter.

\subsection{Quantities of interest}

To capture the variability in turbine response that results from parameter variation, several QoIs were identified. These QoIs are summarized in Table 1 and include the blade, drive- train, and tower loads; blade-tip displacement; and turbine power. Ultimate and fatigue loads were considered for all load QoIs, whereas only ultimate values were considered for blade-tip displacements. The ultimate loads were estimated using the average of the global absolute maximums across all turbulence seeds for a given set of parameter values. The fatigue loads were estimated using aggregate damage-equivalent loads (DEL) of the QoI response across all seeds for a given set of short-term parameter values. For the bending moments, the ultimate loads were calculated as the largest vector sum of the first two components listed, rather than considering each individually. The QoI sensitivity of each input parameter is examined using the procedure summarized in the next section.

\section{Sensitivity analysis procedure}

\subsection{Sensitivity analysis approaches}

There are many different approaches to assess the sensitivity of QoIs for a given input parameter. The best choice depends on the number of considered input parameters, simulation computation time, and availability of parameter distributions. Sensitivity is commonly assessed through the Sobol sensitivity (Saltelli et al., 2008), which decomposes the variance of the response into fractions that can be attributed to different input parameters and parameter interactions. The drawback of this method is the large computational expense, which requires a Monte Carlo analysis to calculate the sensitivity. To decrease the computational expense, one approach is to use a metamodel, which is a lower-order surrogate model trained on a subset of simulations to capture the trends of the 
Table 1. Quantities of interest examined in the sensitivity analyses.

\begin{tabular}{l|lll}
\hline Quantity of interest & \multicolumn{3}{c}{ Components } \\
\hline Blade-root moments & Out-of-plane (OoP) bending & In-plane (IP) bending & Pitching moment \\
Low-speed shaft moments at main bearing & $0^{\circ}$ bending & $90^{\circ}$ bending & Shaft torque \\
Tower-top moment & Fore-aft (FA) bending & Side-side (SS) bending & Yaw moment \\
Tower-base moment & FA bending & SS bending & \\
Blade-tip displacement & OoP deflection (ultimate only) & & \\
Electrical power & & & \\
\hline
\end{tabular}

full-order more computationally expensive model. This approach has been used in the wind energy field (Nelson et al., 2003; Rinker, 2016; Sutherland, 2002; Ziegler and Muskulus, 2016) but was deemed unsuitable for this work given the wind turbine model complexity and associated QoIs. Specifically, it may be difficult for a metamodel to capture the system nonlinearities and interaction of the controller, especially ultimate loads at the tails of the load distribution, limiting metamodel accuracy. Another approach to reduce computational expense is to use a design of experiments approach to identify the fewest simulations needed to capture the variance in the parameters and associated interactions, e.g., Latin hypercube sampling (Matthaus et al., 2017; Saranyasoontorn and Manuel, 2006, 2008) and fractional factorial analysis (Downey, 2006). These methods were considered for this application but such approaches are still too computationally expensive given the large number of considered input parameters. Instead, a screening approach was determined to be the best approach. A screening method provides a sensitivity measure that is not a direct estimate of the variance, but rather supplies a ranking of those parameters with the most influence. One of the most commonly used screening approaches is EE analysis (Campolongo et al., 2007, 2011; Francos et al., 2003; Gan et al., 2014; Huang and Pierson, 2012; Jansen, 1999; Martin et al., 2016; Saint-Geours and Lilburne, 2010; Sohier et al., 2015). Once the EE analysis identifies the input parameters that are most influential to the QoIs, a more targeted analysis can be performed using one of the other sensitivity analyses discussed above.

\subsection{Overview of elementary effects}

$\mathrm{EE}$ at its core is a simple methodology for screening parameters. It is based on the one-at-a-time approach in which each input parameter of interest is varied individually while holding all other parameters fixed. A derivative is then calculated based on the level of change in the QoI to the change in the input parameter using first-order finite differencing. Approaches such as these are called local sensitivity approaches because they calculate the influence of a single parameter without considering interaction with other parameters. However, the EE method extends this process by examining the change in response for a given input parameter at different locations (points) in the input parameter hyperspace. In other

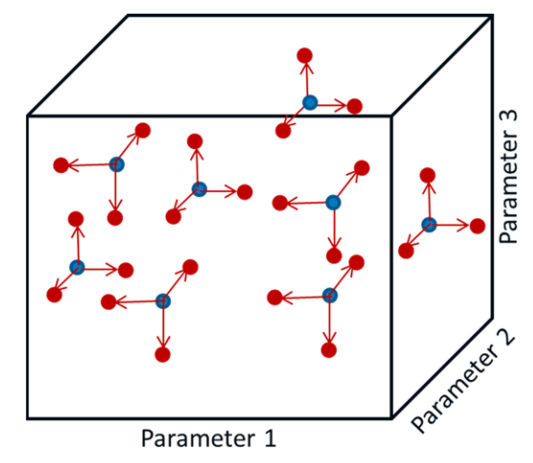

Figure 2. Radial EE approach representation for three input parameters. Blue circles indicate starting points in the parameter hyperspace. Red points indicate variation in one parameter at a time. Each variation is performed for $10 \%$ of the range over which the parameter may vary, either in the positive or negative direction.

words, only one parameter is varied at a time, but this variation is performed multiple times using different values for the other input parameters, as shown in Fig. 2. The derivatives calculated from the different points are considered to assess an overall level of sensitivity. Thus, the EE method considers the interactions between different parameters and is therefore considered a global sensitivity analysis method.

Each wind turbine QoI, $Y$, is represented as a function of different characteristics of the wind or model property input parameters, $\boldsymbol{U}$, as follows:

$Y=f\left(u_{1}, \ldots, u_{i}, \ldots, u_{I}\right)$,

where $I$ is the total number of input parameters. In the general EE approach, all input parameters are normalized between 0 (minimum value) and 1 (maximum value). For a given sampling of $\boldsymbol{U}$, the $\mathrm{EE}$ value of the input parameter, $i$, is found by varying only that parameter by a normalized amount, $\Delta$ :

$\mathrm{EE}_{i}=\frac{f\left(\boldsymbol{U}+\boldsymbol{x}_{k}\right)-f(\boldsymbol{U})}{\Delta}$,

where

$\boldsymbol{x}_{k}= \begin{cases}0 & \text { for } k \neq i, \\ \Delta & \text { for } k=i .\end{cases}$ 
Because of the normalization of $\boldsymbol{U}$, the $\mathrm{EE}$ value $\left(\mathrm{EE}_{i}\right)$ can be thought of as the local partial derivative of $Y$ with respect to an input $\left(u_{i}\right)$, scaled by the range of that input. Thus, the EE value has the same unit as the output QoI. The EE value is calculated for $R$ starting points in the input parameter hyperspace, creating a set of $R$ different calculations of EE value for each input parameter.

The basic approach for performing an EE analysis has been modified over the years to ensure that the input hyperspace is being adequately sampled and to eliminate issues that might confound the sensitivity assessment. In this work, the following modifications to the standard approach were made:

1. A radial approach, where the EE values were calculated by varying each parameter one at a time from a starting point (see Fig. 2), was used rather than the traditional trajectories for varying all of the parameters, which has been shown to improve the efficiency of the method (Campolongo et al., 2011).

2. Sobol numbers were used to determine the initial points at which the derivatives will be calculated (blue circles in Fig. 2), which ensures a wide sampling of the input hyperspace (Campolongo et al., 2011; Robertson et al., 2018).

3. A set delta value equal to $10 \%$ of the input parameter range $\left(\Delta= \pm 0.1\right.$ normalized or $\Delta_{i b}= \pm 0.1 u_{i b \text {,range }}$ dimensional) was used to ensure the calculation of the finite difference occurred over an appropriate range to better meet the assumption of linearity.

4. A modified EE formula - different for ultimate and fatigue loads - was used to examine the sensitivity of the parameters across multiple wind speed bins. EE modifications are detailed in Sect. 3.3.1 and 3.3.2.

5. The most sensitive inputs were identified via thresholding of EE values rather than the classical method involving mean and standard deviation of $\mathrm{EE}$ values, as detailed in Sect. 3.4 and Appendix A.

\subsection{Elementary effects formulas}

This section provides the detailed formulas used to calculate the EE values for the ultimate and fatigue loads.

\subsubsection{Ultimate loads}

When considering the ultimate loads, only the single highest ultimate load is of concern, regardless of the wind speed bin. Therefore, the standard EE formula is modified so that the sensitivity of the parameters can be examined consistently across different wind speed bins. This is accomplished by keeping $\boldsymbol{U}$ and $\Delta$ dimensional (i.e., not making $\boldsymbol{U}$ dimensionless between 0 and 1), multiplying the derivative - approximated with a finite difference - by the total range of the input for a given wind speed bin, and adding the nominal value of the QoI associated with IEC turbine class I and turbulence category B (IEC Class IB) for the given wind speed bin. The EE of input parameter $U_{i b}^{r}$ for a certain QoI, $Y$, at starting point $r$ in wind speed bin $b$ is then given by

$\mathrm{EE}_{i b}^{r}=\left|\frac{Y\left(\boldsymbol{U}^{r}+\boldsymbol{x}_{k}\right)-Y\left(\boldsymbol{U}^{r}\right)}{\Delta_{i b}} u_{i b, \text { range }}\right|+\bar{Y}_{b}$,

where $\bar{Y}_{b}$ represents the IEC Class IB nominal value for the given wind speed bin. The ultimate load, $Y(\boldsymbol{U})$, is defined as the mean of the absolute maximum of the temporal response load in bin $b$ across $S$ seeds for a certain input parameter $i$ and starting point $r$ :

$Y\left(\boldsymbol{U}^{r}\right)=\frac{1}{S} \sum_{s=1}^{S} \operatorname{MAX}\left(\left|Y\left(\boldsymbol{U}^{r}\right)\right|\right)$.

\subsubsection{Fatigue loads}

To compute the fatigue loads, the same basic formulation is used as for the ultimate loads but the DEL of the temporal response is considered in place of the mean of the absolute maximums:

$\mathrm{EE}_{i b}^{r}=P\left(v_{b}\right)\left|\frac{\operatorname{DEL}\left(\boldsymbol{U}^{r}+\boldsymbol{x}_{k}\right)-\operatorname{DEL}\left(\boldsymbol{U}^{r}\right)}{\Delta_{i b}} u_{i b, \text { range }}\right|$,

where $\operatorname{DEL}\left(\boldsymbol{U}^{r}\right)$ is the aggregate of the short-term DEL of a given QoI across all seeds computed using the NREL postprocessing tool, MLife (Hayman and Buhl, 2012). DELs are computed without the Goodman correction and with load ranges about a zero fixed mean. The fatigue EE value is scaled by $P\left(v_{b}\right)$, which is the Rayleigh probability at the wind speed $v_{b}$ (assuming IEC Class IB turbulence) associated with bin $b$ to compare the fatigue loads consistently across wind speed bins.

\subsection{Identification of most sensitive inputs}

The EE value is a surrogate for a sensitivity level. Therefore, a higher EE value for a given input parameter indicates more sensitivity. Here, the most sensitive parameters are identified by defining a threshold over which an individual EE value would be considered significant, indicating the sensitivity of the associated parameter. This approach differs from the classical method of determining parameter sensitivity, as discussed in Appendix A. The threshold is set individually for each QoI. For the wind parameter study, the threshold is defined as $\overline{\mathrm{EE}^{r}}+2 \sigma$, where $\overline{\mathrm{EE}^{r}}$ is the mean of all EE values across all starting points $R$, inputs $I$, and wind speed bins $B$ for each QoI and $\sigma$ is the standard deviation of these EE values. For the turbine parameter study, the results are stratified based on wind speed bin. Therefore, the threshold for this study is modified to $\overline{\mathrm{EE}^{r}}+1.7 \sigma$. Additionally, the ultimate load thresholds for the turbine parameter study are computed 
Table 2. Wind-inflow condition parameters (18 total).

\begin{tabular}{llll}
\hline $\begin{array}{l}\text { Mean mind } \\
\text { profile }\end{array}$ & $\begin{array}{l}\text { Velocity } \\
\text { spectrum }\end{array}$ & $\begin{array}{l}\text { Spatial } \\
\text { coherence }\end{array}$ & $\begin{array}{l}\text { Component } \\
\text { correlation }\end{array}$ \\
\hline Shear $(\sigma)$ & $\begin{array}{l}\text { Standard deviation } \\
\left(\sigma_{u}, \sigma_{v}, \sigma_{w}\right)\end{array}$ & $\begin{array}{l}\text { Input coherence decrement } \\
\left(a_{u}, a_{v}, a_{w}\right)\end{array}$ & $\begin{array}{l}\text { Reynolds stress } \\
\left(\mathrm{PC}_{u w}, \mathrm{PC}_{u v}, \mathrm{PC}_{v w}\right)\end{array}$ \\
\hline Veer $(\beta)$ & $\begin{array}{l}\text { Integral scale parameter } \\
\left(L_{u}, L_{v}, L_{w}\right)\end{array}$ & $\begin{array}{l}\text { Offset parameter } \\
\left(b_{u}, b_{v}, b_{w}\right)\end{array}$ & \\
& & Exponent $(\gamma)$ & \\
\hline
\end{tabular}

using only near- and above-rated results because of the separation of EE values between the below-, near-, and aboverated wind speed bins. For both studies, fatigue load EE values are not clearly separated by wind speed; therefore, all wind speeds are used to compute the fatigue load parameter thresholds.

\section{Results}

Two separate case studies were performed to assess the sensitivity of input parameters to the resulting ultimate and fatigue loads of the NREL $5 \mathrm{MW}$ wind turbine. The categories of input parameters analyzed were the wind-inflow conditions and the aeroelastic turbine properties. In both of the case studies, loads were analyzed for three wind speed bins, using mean wind speed bins of 8,12 , and $18 \mathrm{~m} \mathrm{~s}^{-1}$, representing below-, near-, and above-rated wind speed bins, respectively. Turbulent wind conditions were generated using IEC Kaimal turbulence spectra with exponential spatial coherence functions. For the turbine parameter study, turbulence was based on IEC Class IB turbulence. Correlations and joint distributions of the parameters were not considered because developing this relationship for so many parameters would be difficult or impossible. In addition, the correlation could be very different for different wind sites. The impact of not considering the correlation was limited by choosing parameters that were fairly independent of one another when possible, and by binning the results by wind speed.

\subsection{Wind-inflow characteristics}

Many researchers have examined the influence of wind characteristics on turbine load response, considering differing wind parameters and turbulence models, and using different methods to assess their sensitivity. The most common parameter considered is the influence of turbulence intensity variability, which past work has shown to have significant variability and a large impact on the turbine response (Dimitrov et al., 2015; Downey, 2006; Eggers et al., 2003; Ernst and Seume, 2012; Holtslag et al., 2016; Kelly et al., 2014; Matthaus et al., 2017; Moriarty et al., 2002; Rinker, 2016; Saranyasoontorn and Manuel, 2008; Sathe et al., 2012; Sutherland, 2002; Wagner et al., 2010; Walter et al., 2009). The shear exponent, or wind profile, is the next most common parameter examined, concluded to have similar or slightly less importance to the turbulence intensity (Bulaevskaya et al., 2015; Dimitrov et al., 2015; Downey, 2006; Eggers et al., 2006; Ernst and Seume, 2012; Kelly et al., 2014; Matthaus et al., 2017; Sathe et al., 2012). Other parameters investigated include the turbulence length scale, standard deviation of different directional wind components, Richardson number, spatial coherence, component correlation, and veer. Mixed conclusions are drawn on the importance of these secondary parameters, which are influenced by the range of variability considered (based on the conditions examined), the turbine control system, and the turbine size and hub height under consideration. The effects of considering the secondary wind parameters are also mixed, sometimes increasing and sometimes decreasing the loads in the turbine; however, most agree that the use of site-specific measurements of the wind parameters will lead to a more accurate assessment of the turbine loads, resulting in designs that are either further optimized or lower risk.

The focus of this case study is to obtain a thorough assessment of which wind characteristics influence wind turbine structural loads when considering the variability of these parameters over a wide sampling of site conditions.

\subsubsection{Parameters}

A total of 18 input parameters were chosen to represent the wind-inflow conditions, considering the mean wind profile, velocity spectrum, spatial coherence, and component correlation, as summarized in Table 2. The parameters used were identified considering a Veers model for describing and generating the wind characteristics because it provides a quantitative description with a known and limited set of inputs. Each of these parameters is described in the following subsections. Note that the Veers model differs from the other commonly used Mann turbulence model. ${ }^{1}$ Regardless, the

\footnotetext{
${ }^{1}$ The Mann turbulence model (also considered in the IEC 614001 standard) is based on a three-dimensional tensor representation of the turbulence derived from rapid distortion of isotropic turbulence using a uniform mean velocity shear (Jonkman, 2009). The Mann model considers the three turbulence components as dependent, representing the correlation between the longitudinal and vertical com-
} 
Veers model is used here because it is more tailorable than the Mann model, i.e., there are more input parameters that can be varied.

\section{Mean wind profile}

A standard power-law shear model is used to describe the vertical wind speed profile and a linear wind direction veer model is used. The sensitivity of these characteristics are captured through variation in the exponent of the shear, $\alpha$, and the total veer across the turbine, $\beta$ (centered around the hub, following right-hand rule about the vertical axis of the turbine). The IEC 61400-1 standard (IEC, 2005) uses $\alpha=0.2$ and $\beta=0^{\circ}$ under normal turbulence.

\section{Velocity spectrum}

The Veers model uses a Kaimal spectrum to represent the turbulence. The Kaimal spectrum is defined as (IEC, 2005):

$$
\frac{f S_{q}(f)}{\sigma_{q}^{2}}=\frac{4 f L_{q} / V_{\mathrm{hub}}}{\left(1+6 f L_{1} / V_{\mathrm{hub}}\right)^{5 / 3}},
$$

where $f$ is the frequency, $q$ is the index of the velocity component direction $(u, v, w), S_{q}$ is the single-sided velocity spectrum, $V_{\text {hub }}$ is the mean wind speed at hub height, $\sigma_{q}$ is the velocity component standard deviation, and $L_{q}$ is the velocity component integral scale parameter. The IEC 61400-1 standard (IEC, 2005) uses a wind-speed-dependent standard deviation, i.e., $\sigma_{u}=0.14 \times\left(0.75 V_{\text {hub }}+5.6 \mathrm{~m} \mathrm{~s}^{-1}\right)$, and a set scaling between the direction components of the standard deviation and scale parameters, i.e., $\sigma_{v}=0.8 \sigma_{u} ; \sigma_{w}=0.5 \sigma_{u}$; $L_{u}=8.1 \times(42 \mathrm{~m})=340.2 \mathrm{~m} ; L_{v}=2.7 \times(42 \mathrm{~m})=113.4 \mathrm{~m}$; and $L_{w}=0.66 \times(42 \mathrm{~m})=27.72 \mathrm{~m}$. However, in this study each parameter in velocity component direction $(u, v, w)$ is varied independently. An inverse Fourier transform is applied to the Kaimal spectrum and random phases derived from the turbulence seed to determine a turbulent time series for each of the wind components independently.

\section{Spatial coherence model}

The point-to-point spatial coherence (Coh) quantifies the frequency-dependent cross-correlation of a single turbulence component at different transverse points in the wind inflow grid. The general coherence model used in TurbSim is defined as

$\operatorname{Coh}_{q, f}=\exp \left(-a_{q}\left(\frac{d}{z_{\mathrm{m}}}\right)^{\gamma} \sqrt{\left(\frac{f d}{V_{\mathrm{hub}}}\right)^{2}+\left(b_{q} d\right)^{2}}\right)$,

ponents resulting from the Reynolds stresses. In the IEC 61400-1 standard, the two spectra (Mann and Kaimal) are equated, resulting in three parameters that may be set for the Mann model. However, there is uncertainty in whether the loads resulting from these two different turbulence spectra are truly consistent. where $d$ is the distance between points $i$ and $j, z_{\mathrm{m}}$ is the mean height of the two points (IEC, 2005), and $V_{\text {hub }}$ is the mean wind speed at hub height. The variables $a_{q}$ and $b_{q}$ are the input coherence decrement and offset parameter, respectively. Note that the use of $V_{\text {hub }}$ in the general coherence model is a modification to the standard TurbSim method. The model is based on the IEC coherence model with the added factor $\left(d / z_{\mathrm{m}}\right)^{\gamma}$ - introduced by Solari (1987) - where $\gamma$ can vary between 0 and 1 . The IEC 61400- 1 standard (IEC, 2005) does not use the $\left(d / z_{\mathrm{m}}\right)^{\gamma}$ factor and uses $a_{u}=12$ and $b_{u}=0.12 / L_{u}$. Spatial coherence is not defined in the standard (IEC, 2005) for the transverse wind components $v$ and $w$.

\section{Component correlation model}

The component-to-component correlation (PC) quantifies the cross-correlation between directional turbulence components at a single point in space. For example, $\mathrm{PC}_{u w}$ quantifies the correlation between the $u$ - and $w$-turbulence components at a given point. TurbSim modifies the $v$ - and $w$-component wind speeds by computing a linear combination of the time series of the three independent wind speed components to obtain the mean Reynolds stresses $\left(\mathrm{PC}_{u w}, \mathrm{PC}_{u v}\right.$, and $\left.\mathrm{PC}_{v w}\right)$ at the hub. Note that because this calculation occurs in the time domain, the velocity spectra of the $v$ and $w$ components are somewhat affected by the enforced component correlations. The IEC 61400-1 standard (IEC, 2005) does not specify Reynolds stresses.

\subsubsection{Parameter ranges}

To assess the sensitivity of each of the parameters on the load response, a range over which the parameters could vary was defined. The variation level was assessed through a literature search seeking the range over which the parameters could realistically vary for different installation sites around the world (Berg et al., 2013; Bulaevskaya et al., 2015; Clifton, 2014; Dimitrov, 2018; Dimitrov et al., 2015; Eggers et al., 2003; Ernst et al., 2012; Holtslag et al., 2016; Jonkman, 2009; Kalverla et al., 2017; Kelley, 2011; Lindelöw-Marsden, 2009; Matthaus et al., 2017; Moriarty et al., 2002; Moroz, 2017; Nelson et al., 2003; Park et al., 2015; Rinker, 2016; Saint-Geours and Lilburne, 2010; Saranyasontoorn et al., 2004; Saranyasontoorn and Manuel, 2008; Sathe et al., 2012; Solari, 1987; Sutherland, 2002; Teunissen, 1970; Wagner et al., 2010; Walter et al., 2009; Wharton et al., 2015; Ziegler et al., 2016). When possible, parameter ranges were set based on wind speed bins. If no information on wind speed dependence was found, the same values were used in all bins. The ranges, summarized in Table 3, were taken from multiple sources (references cited below the values), based on measurements across a variety of different locations and conditions. For comparison, the nominal value prescribed by IEC for category B turbulence is specified in the "Nom." row. 


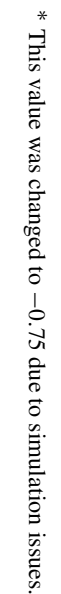

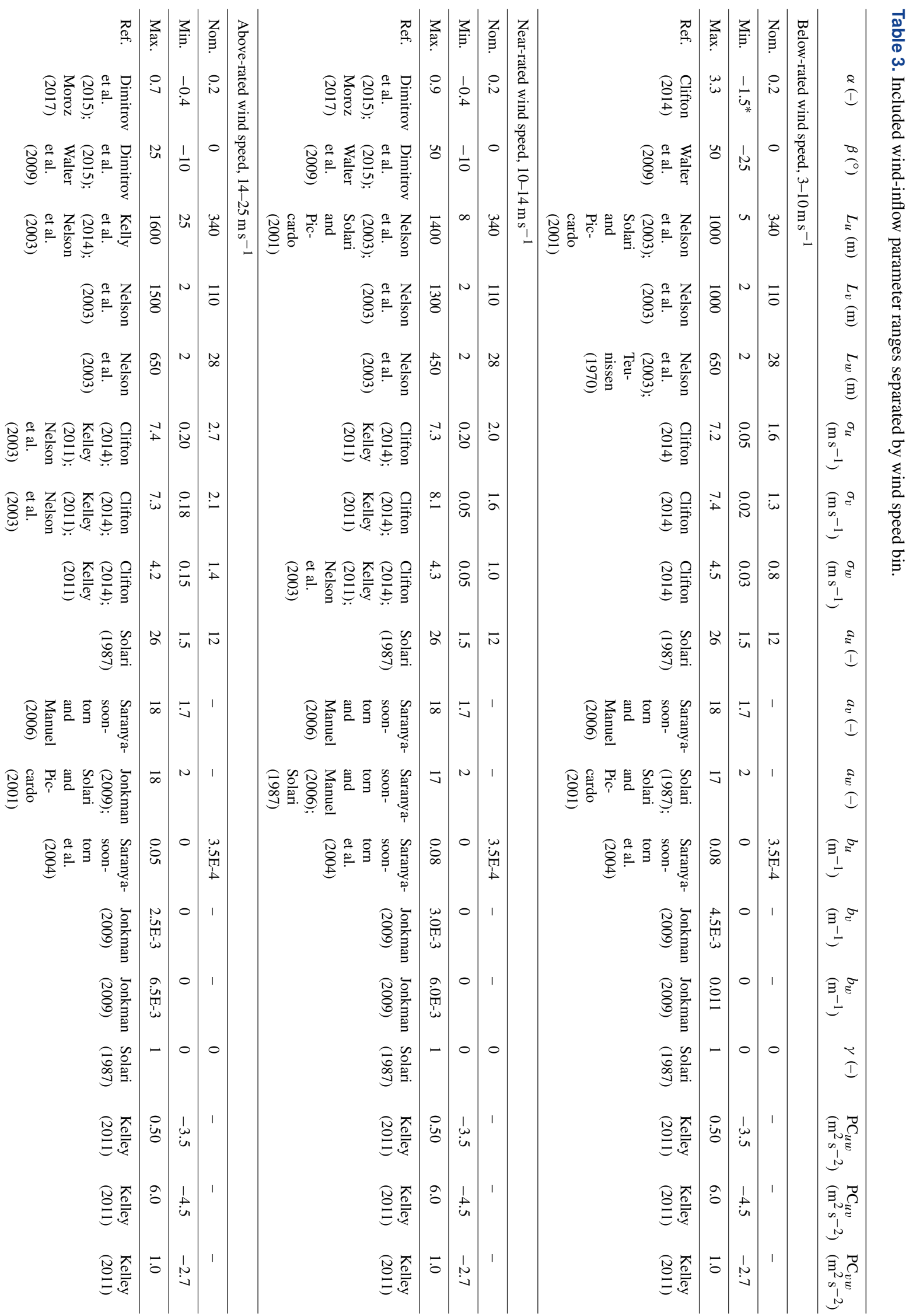



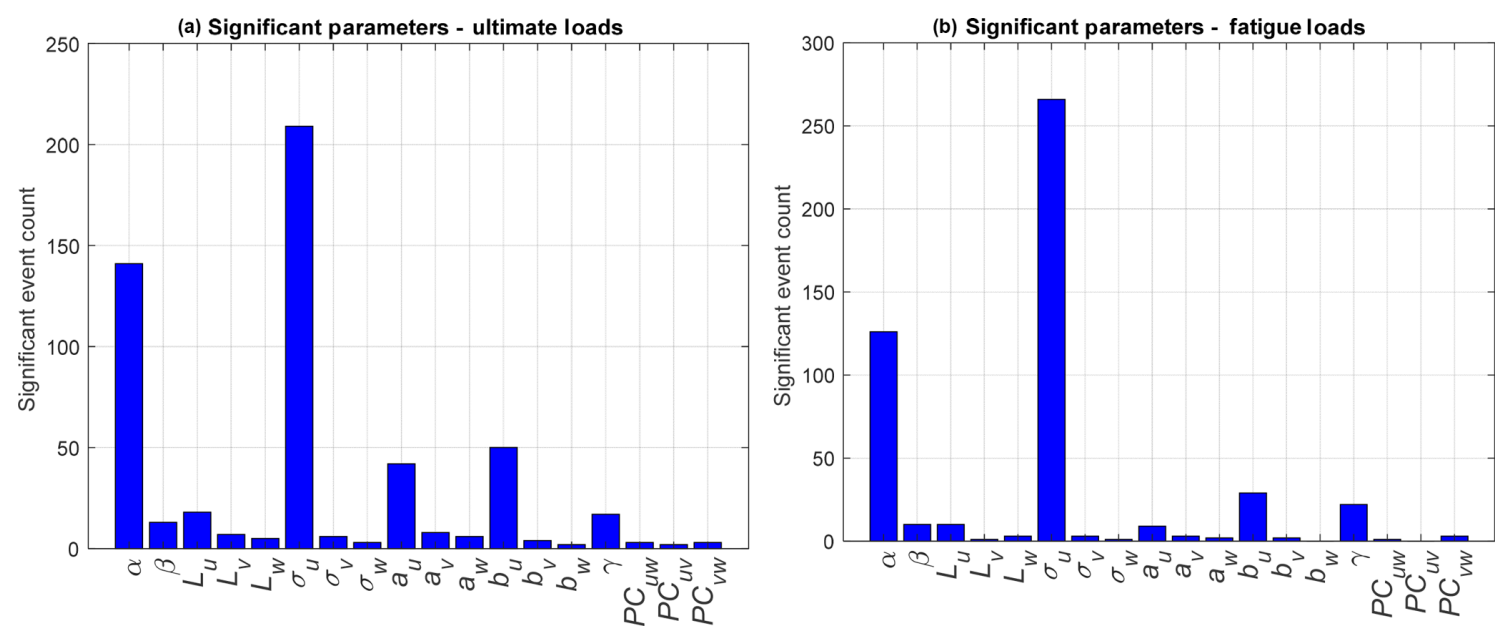

Figure 3. Identification of significant parameters using ultimate (a) and fatigue (b) loads. Significant events are defined by the number of outliers identified across each of the QoIs for all wind speed bins, input parameters, and simulation points.

To simplify the screening of the most influential parameters, all parameters were considered independent of one another. This was done because of the difficulty of considering correlations between a large number of parameters. Such correlations should be studied in future work once parameter importance has been established. Because each parameter was considered independently, except for the conditioning on wind speed bin, some nonphysical parameter combinations may arise. This was considered acceptable for the screening process.

\subsubsection{Elementary effects}

The EE value was calculated for each of the 18 input parameters $(I)$ at 30 different starting points $(R)$ in the inputparameter hyperspace. The number of points was determined through a convergence study on the average of the EE value. At each of the points examined, $S$ different turbulent wind files (i.e., $S$ independent time-domain realizations from $S$ seeds) were run. Thirty seeds were needed based on a convergence study of the ultimate and fatigue load metrics for all QoIs. Based on these turbine parameters, the total number of simulations performed for the wind-inflow case study was $R \times(I+1) \times S \times B=30 \times 19 \times 30 \times 3=51300$, where $B$ is the number of wind speed bins considered.

The EE values across all input parameters, input hyperspace points, and wind speed bins were examined for each of the QoIs for ultimate and fatigue loads. To identify the most sensitive parameters, a tally was made of the number of times an EE value exceeded the threshold for a given QoI. The resulting tallies are shown in Fig. 3, with the ultimate load tally on the left and the fatigue load tally on the right. As expected, based on the parameters of importance in IEC design standards, these plots show an overwhelming level of sensitivity of the $u$-direction turbulence standard deviation $\left(\sigma_{u}\right)$ and also the vertical wind shear $(\alpha)$. However, focusing on the lower tally values in this plot highlights the secondary level of importance of veer $(\beta), u$-direction integral length $\left(L_{u}\right)$, and components of the IEC coherence model $\left(a_{u}\right.$ and $\left.b_{u}\right)$ as well as the exponent $(\gamma)$.

Histograms of the EE values for each of the QoIs are plotted in Figs. 4 and 5 for the ultimate and fatigue load metrics (associated exceedance probability plots are shown in Appendix B, Figs. B1 and B2). Each plot contains all calculated EE values for a given QoI colored by wind speed bin. The threshold used to identify significant EE values is shown in each plot as a solid black line. All points above the threshold line indicate a significant event and are included in the outlier tally for each QoI. Note that although electric power is shown, it is not used in the outlier tally because its variation is strictly limited by the turbine controller rather than other wind parameters. Highlighted in these figures is that most of the outliers come from the below-rated wind speed bin.

To understand why the below-rated wind speed bin would be creating the most outliers, a more thorough examination was made for one of the QoIs. Exceedance probability plots of blade-root loads are shown in Fig. 6. Here, all input parameters are plotted independently of each other to compare the behavior between parameters. Each line represents a different input parameter with each point representing a different location in the hyperspace. These plots show how the shear and $u$-component standard deviation for the lower wind speed bin stand out compared to all other parameters; likewise, the $u$-component standard deviation stands out across different wind speed bins for the ultimate load. One of the reasons that the shear value shows such a large sensitivity in the lowest wind speed bin is the large range over which the parameter is varied. A smaller range is used for the nearand above-rated bins, resulting in less sensitivity to shear for those wind speeds. The impact of the range on the sensitivity 

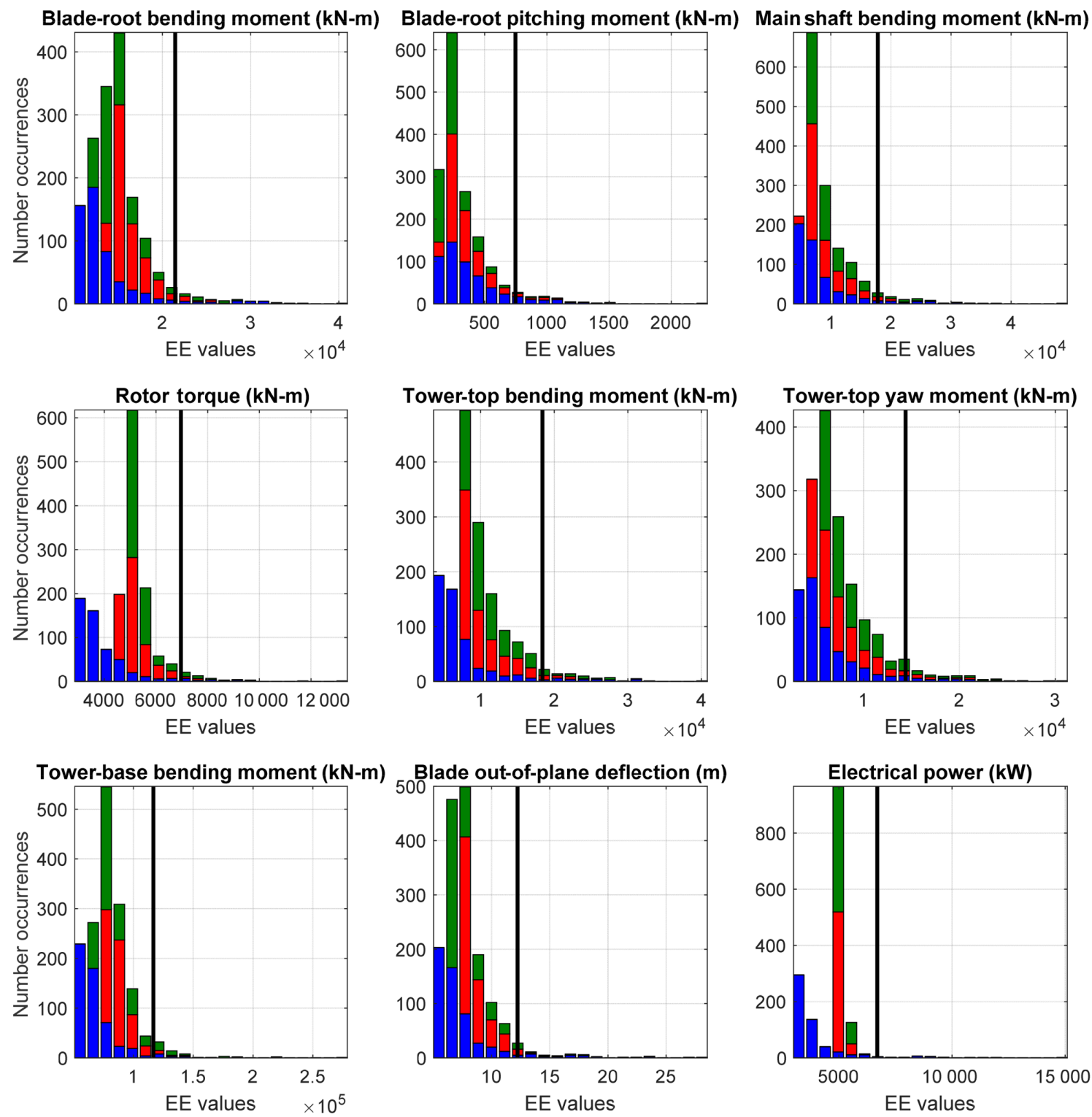

Figure 4. Stacked histogram of the ultimate load EE values for each of the QoIs across all wind speed bins, input parameters, and simulation points. Black line represents the defined threshold by which outliers are counted for each QoI. Color indicates wind speed bin (blue is below-rated speed, red is near-rated speed, green is above-rated speed).

Table 4. Primary input parameters contributing to ultimate load sensitivity of each QoI. Values indicate the number of times the variable contributes to the sensitivity count.

\begin{tabular}{rrrrrrrr}
\hline $\begin{array}{r}\text { Blade-root } \\
\text { bending mom. }\end{array}$ & $\begin{array}{r}\text { Blade-root } \\
\text { pitch mom. }\end{array}$ & $\begin{array}{r}\text { Main shaft } \\
\text { bending mom. }\end{array}$ & $\begin{array}{r}\text { Rotor } \\
\text { torque }\end{array}$ & $\begin{array}{r}\text { Tower-top } \\
\text { bending mom. }\end{array}$ & $\begin{array}{r}\text { Tower-top } \\
\text { yaw mom. }\end{array}$ & $\begin{array}{r}\text { Tower-base } \\
\text { bending mom. }\end{array}$ & $\begin{array}{r}\text { Blade OoP } \\
\text { deflection }\end{array}$ \\
\hline$\sigma_{u}(29)$ & $\sigma_{u}(26)$ & $\alpha(33)$ & $\sigma_{u}(28)$ & $\alpha(31)$ & $\sigma_{u}(41)$ & $\sigma_{u}(22)$ & $\alpha(22)$ \\
\hline$\alpha(22)$ & $\gamma(10)$ & $\sigma_{u}(28)$ & $\alpha(12)$ & $\sigma_{u}(22)$ & $\alpha(10)$ & $a_{u}, b_{u}, L_{u}(8)$ & $\sigma_{u}(13)$ \\
\hline$b_{u}(7)$ & $L_{u}(8)$ & $a_{u}, b_{u}(5)$ & $b_{u}(6)$ & $a_{u}, b_{u}(5)$ & $a_{u}, b_{u}(8)$ & $b_{u}(9)$ \\
\hline
\end{tabular}



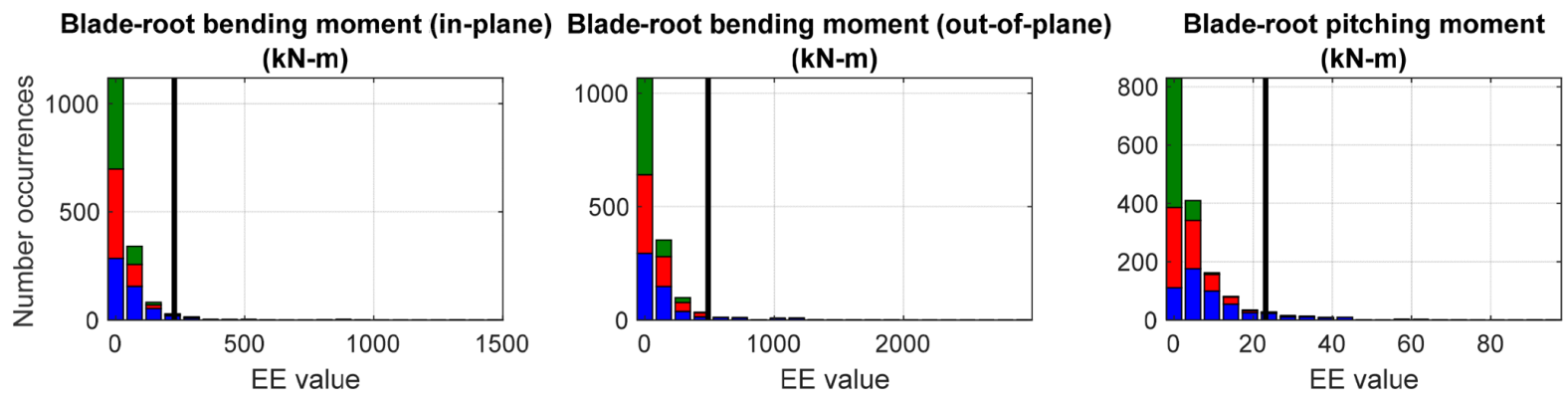

Main shaft bending moment (0-degree) Main shaft bending moment (90-degree)

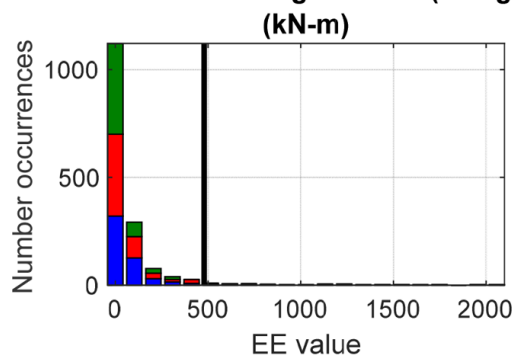

(kN-m)

Rotor torque

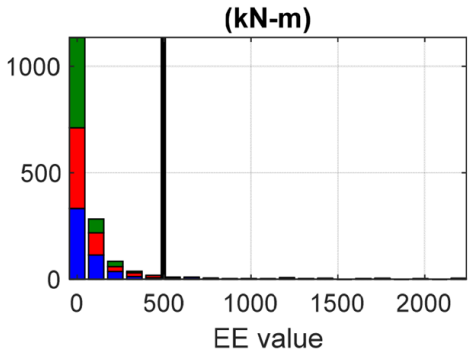

(kN-m)

Tower-top bending moment (fore-aft)
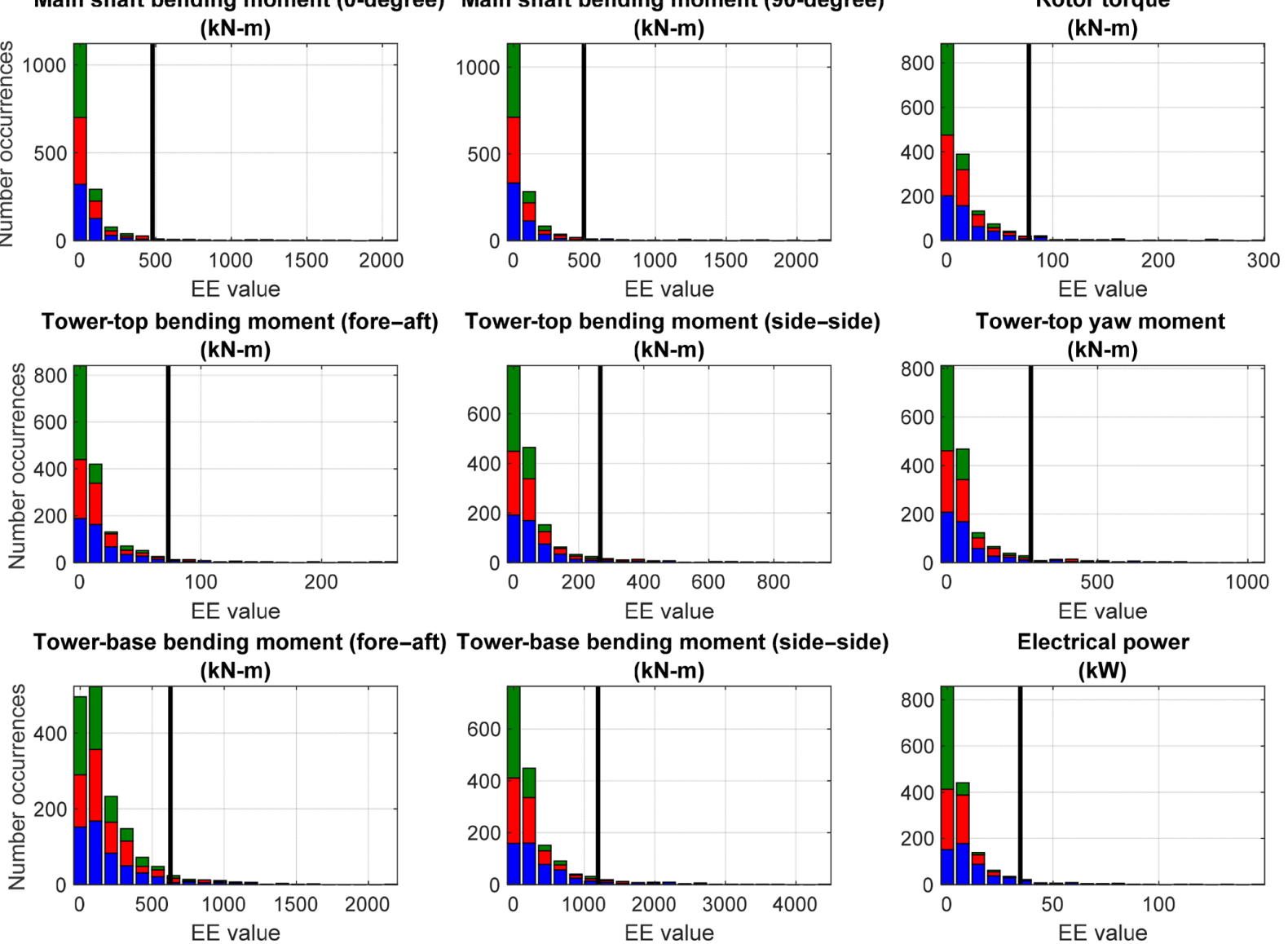

Figure 5. Stacked histogram of the fatigue load EE values for each of the QoIs across all wind speed bins, input parameters, and simulation points. Black line represents the defined threshold by which outliers are counted for each QoI. Color indicates wind speed bin (blue is below-rated speed, red is near-rated speed, green is above-rated speed).

Table 5. Primary input parameters contributing to fatigue load sensitivity of each QoI. Values indicate the number of times the variable contributes to the sensitivity count.

\begin{tabular}{rrrrrrrrrrr}
\hline $\begin{array}{r}\text { Blade-root } \\
\text { IP bend. } \\
\text { moment }\end{array}$ & $\begin{array}{r}\text { Blade-root } \\
\text { OoP pitch. } \\
\text { moment }\end{array}$ & $\begin{array}{r}\text { Blade-root } \\
\text { pitch. } \\
\text { moment }\end{array}$ & $\begin{array}{r}\text { Main shaft } \\
\text { bending } \\
\text { moment } 0^{\circ}\end{array}$ & $\begin{array}{r}\text { Main shaft } \\
\text { bending } \\
\text { mom. 90 }\end{array}$ & $\begin{array}{r}\text { Rotor } \\
\text { torque }\end{array}$ & $\begin{array}{r}\text { Tower-top } \\
\text { FA bend. } \\
\text { moment }\end{array}$ & $\begin{array}{r}\text { Tower-top } \\
\text { SS bend. } \\
\text { moment }\end{array}$ & $\begin{array}{r}\text { Tower-top } \\
\text { yaw } \\
\text { moment }\end{array}$ & $\begin{array}{r}\text { Tower-base } \\
\text { FA bend. } \\
\text { moment }\end{array}$ & $\begin{array}{r}\text { Tower-base } \\
\text { SS bend. } \\
\text { moment }\end{array}$ \\
\hline$\sigma_{u}(10)$ & $\alpha(14)$ & $\sigma_{u}(14)$ & $\alpha(18)$ & $\alpha(18)$ & $\sigma_{u}(25)$ & $\sigma_{u}(31)$ & $\sigma_{u}(47)$ & $\sigma_{u}(48)$ & $\sigma_{u}(24)$ & $\sigma_{u}(35)$ \\
\hline$\alpha(8)$ & $\sigma_{u}(9)$ & $L_{u}(7)$ & $\sigma_{u}(12)$ & $\sigma_{u}(11)$ & $\alpha(11)$ & $\alpha(12)$ & $\alpha(13)$ & $\alpha(12)$ & $\alpha(6)$ & $\alpha(9)$ \\
\hline$b_{u}(3)$ & $b_{u}(4)$ & $\alpha(5)$ & $\beta(2)$ & $\beta(2)$ & $b_{u}(9)$ & $b_{u}(7)$ & $\gamma(3)$ & $\gamma(3)$ & $\gamma(4)$ & $\gamma(4)$ \\
\hline
\end{tabular}



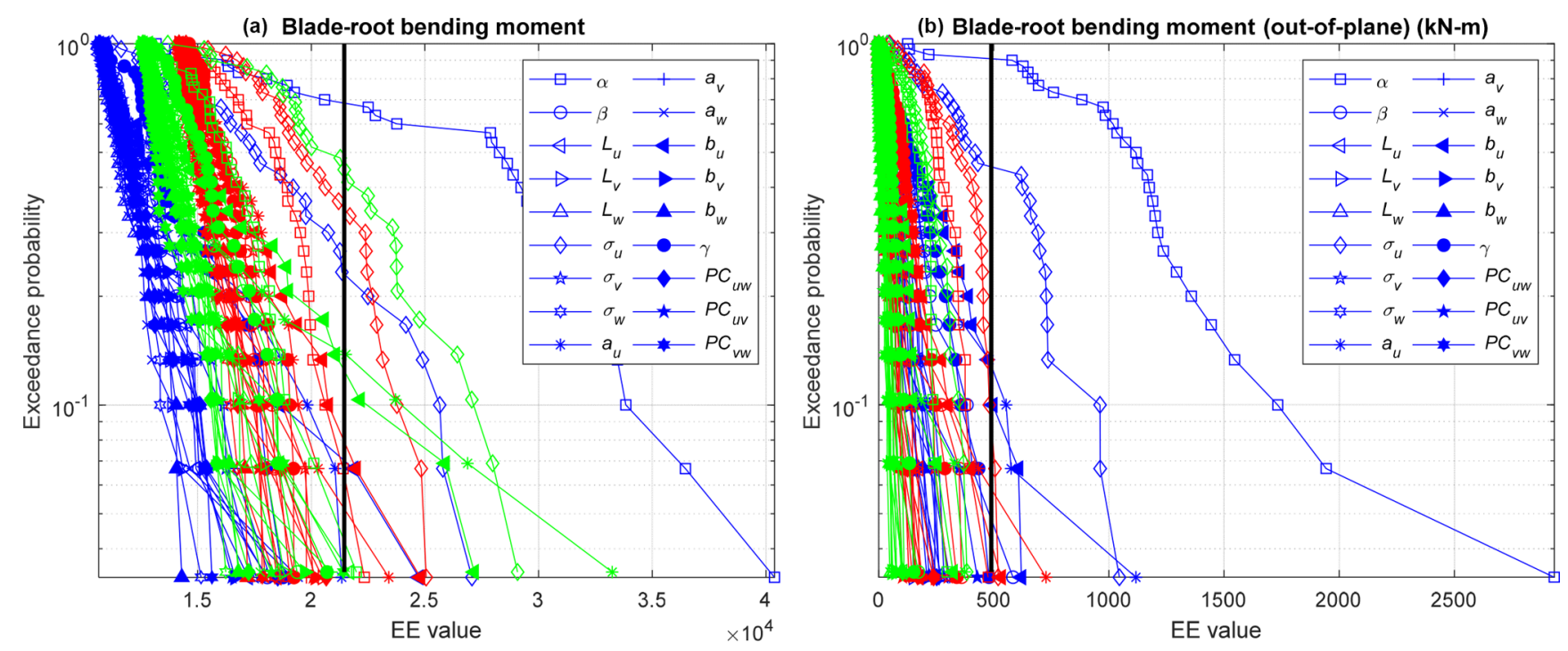

Figure 6. Exceedance probability plot of ultimate (a) and fatigue (b) load EE values for blade-root bending moments. Each line represents a different input parameter and wind speed bin (blue is below-rated speed, red is near-rated speed, green is above-rated speed).

of the parameter indicates that for sites with extreme conditions, such as an extreme shear, using appropriate parameter values in a load analysis can be important in accurately assessing the ultimate and fatigue loading on the turbine. The effect of shear could also be diminished by employing independent blade-pitch control, whereas the reference NREL 5 MW turbine controller used here employs collective bladepitch control.

Histogram plots of blade-root bending moment EE values are shown in Figs. 7 and 8. In each figure, wind speed bins are displayed in different plots and EE value histograms showing the contribution from all input parameters are shown in each histogram. Ultimate load EE values are shown in Fig. 7 and fatigue load EE values are shown in Fig. 8. Highlighted in these plots is the large sensitivity of the shear parameter and, to a lesser extent, $u$-component standard deviation in the far extremes.

To summarize which parameters are important for which QoIs, the number of times each input parameter contributed to the significant event count for a given QoI was tallied. The top most-sensitive parameters are shown in Tables 4 and 5 for ultimate and fatigue loads, respectively. Overall, $46 \%$ of the outliers for both ultimate and fatigue loads are due to $u$-direction turbulence standard deviation $\left(\sigma_{u}\right)$ and $26 \%$ for vertical shear $(\alpha)$; for all but two QoIs, these are the most sensitive parameters. The two exceptions are blade-root pitching moment and tower-base bending moment, which show $u$ direction turbulence standard deviation as the most important parameter, but show coherence properties and integral scale parameter as more important than shear. This is understandable because shear will have little effect on collective blade pitching and rotor thrust. The remaining parameters have far less significance, with only components of the IEC coherence model, $a_{u}(5 \%)$ and $b_{u}(8 \%)$, having a value great than $1 \%$. These results can be used in future sensitivity analysis work to focus on perturbation of specific input parameters based on desired turbine loads.

\subsection{Aeroelastic turbine properties}

The second case study focuses on which aeroelastic turbine parameters have the greatest influence on turbine ultimate and fatigue loads during normal turbine operation. These parameters are categorized into four main property categories: support structure, blade structure, blade aerodynamics, and controller.

It is widely acknowledged that uncertainty in the aerodynamic parameters can affect the prediction of turbine performance and structural loading (Abdallah, 2015; Abdallah et al., 2015; Madsen et al., 2010; Simms et al., 2001). Abdallah et al. (2015) demonstrated the impact of uncertainty in steady airfoil data on prediction of extreme loads and assessed the correlation between various static coefficient polars. Despite significant work to measure these parameters, considerable uncertainty remains in their prediction. Static lift and drag measurements almost exclusively come from wind tunnel tests of airfoils, which lack three-dimensional and unsteady effects that are instead estimated through the application of semiempirical engineering models, e.g., rotational augmentation (stall delay) and stall hysteresis (Abdallah et al., 2015; Simms et al., 2001). In Damiani et al. (2016), unsteady aerodynamic parameters were tuned for several airfoil sections to match experimental lift and drag unsteady hysteresis loops, but the consequences of parameter variation were not considered. Blade chord and twist ranges were chosen using the work of Loeven and Bijl (2008), who identified changes in 

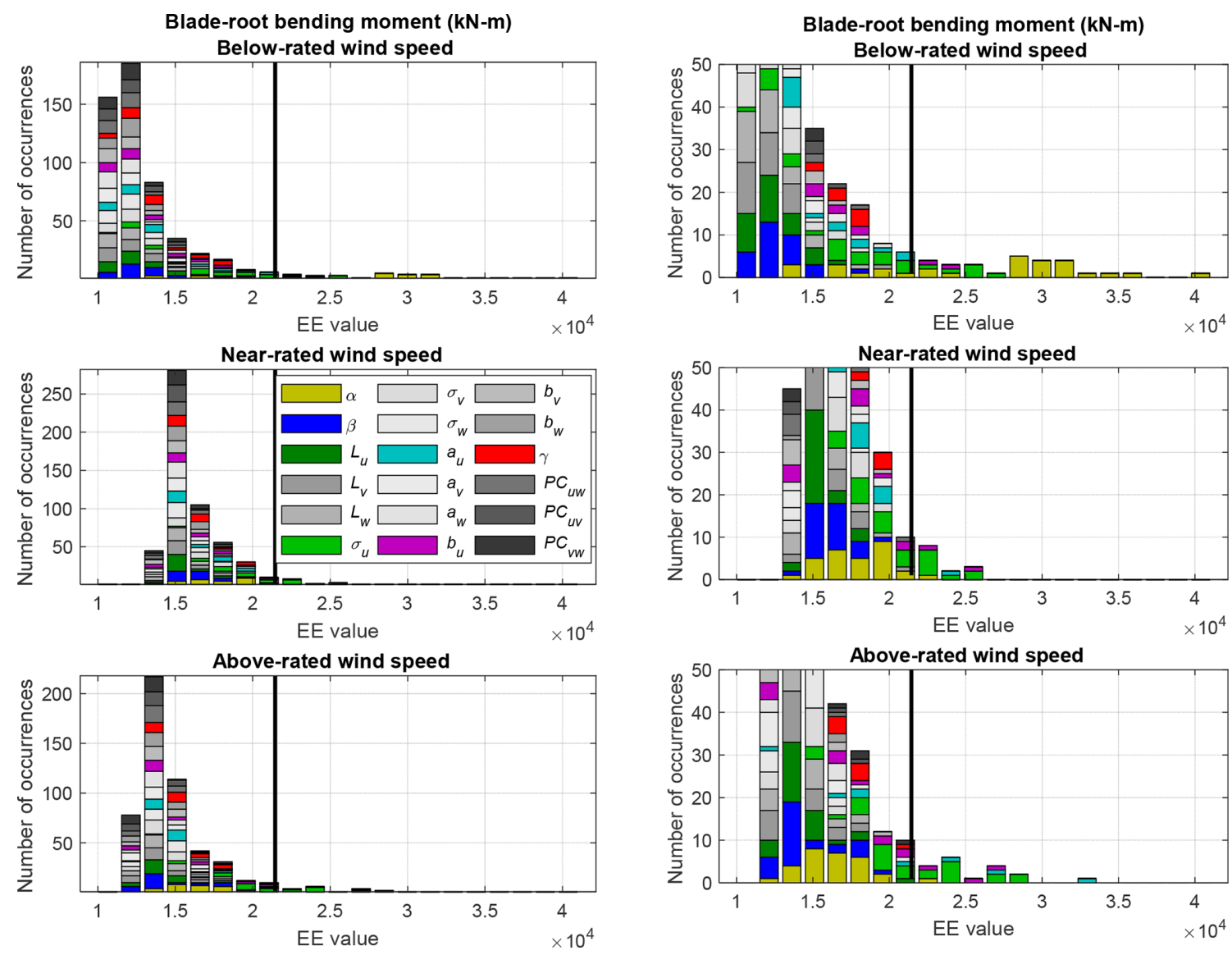

Figure 7. Histograms of ultimate load EE values for the blade-root bending moment. Each graph in the left column shows one wind speed bin and includes all input parameters. Right column is a zoomed-in view of the left.

blade chord and twist based on uncertainty in aerodynamic loading, icing, or wear of the blades.

Beyond the blade aerodynamic properties, other turbine properties also contribute to the uncertainty of the load response characteristics. Abdallah et al. (2015) provides a comprehensive assessment of the sources of uncertainty affecting the prediction of loads in a wind turbine. Researchers have not focused on these other parameters as significantly as the aerodynamic ones, but they could make a significant contribution to the uncertainty. Witcher (2017) examined uncertainty in properties such as the tower and blade mass/stiffness properties within the context of defining a probabilistic approach to designing wind turbines by examining distributions of the load from propagated input parameter uncertainties versus resistance distributions. Prediction of the reliability of the wind turbine has been studied through examination of the damping in the structure by Koukoura (2014) and a better understanding of the uncertainty in the properties of the drivetrain by Holierhoek et al. (2010). Limited information is available on what the actual ranges of uncertainty are for these different characteristics. For most studies, expert opinion is used to set a realistic bound. A better assessment of these bounds will be needed in future work to understand the relative importance of the physical parameters and to provide a more precise assessment of the uncertainty bounds in the load response of wind turbines.

\subsubsection{Parameters}

For the turbine aeroelastic properties, 39 input parameters $(I)$ were identified covering support structure properties, blade structural properties, blade aerodynamic properties (both steady and unsteady characteristics), and controller properties. These parameters are summarized in Table 6 (acronyms are defined in the following subsections).

\subsubsection{Parameter ranges}

The level of variation was based on the perceived level of uncertainty in the parameter values. Some of these levels of uncertainty are proposed within the literature, but when no other information was available expert opinion was used. The source for the information is provided below the values in each table summarizing the parameter ranges. "Exp." is used to identify where expert opinion was used. The uncertainty 

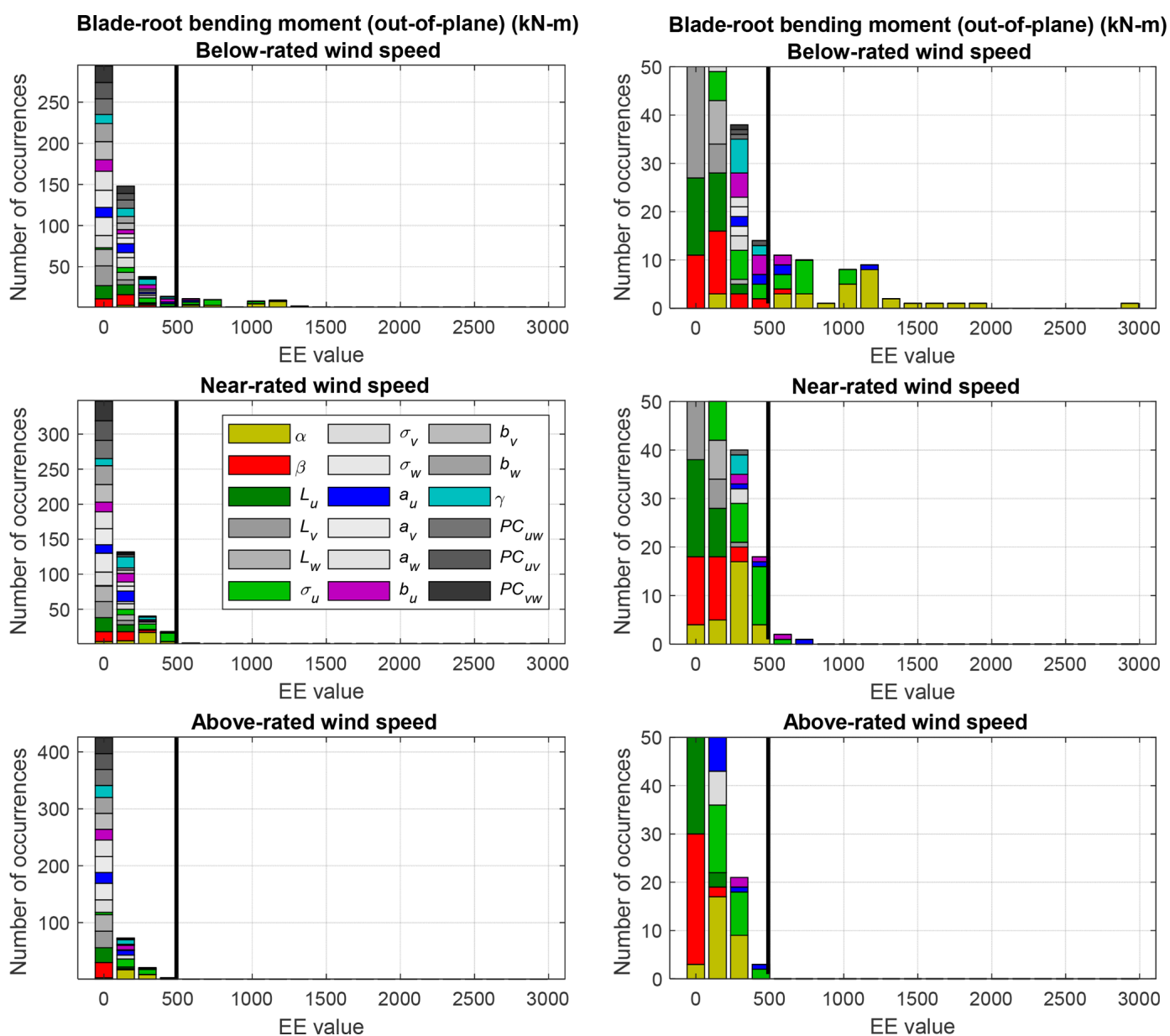

Figure 8. Histograms of fatigue load EE values for the blade-root bending out-of-plane bending moment. Each graph in the left column shows one wind speed bin and includes all input parameters. Right column is a zoomed-in view of the left.

levels are largely percentage based, but in some instances an exact value was used. The following subsections define the ranges of the parameters introduced in Table 6. All parameters were considered independent of one another, as was done for the wind parameter sensitivity analysis.

\section{Support structure properties}

For the support structure, nine parameters were varied and summarized in Table 6 . These parameters included mass and center of mass $(\mathrm{CM})$ of the tower and nacelle, tower and drivetrain stiffness factors, tower and drivetrain damping ratio, and shaft angle. To manipulate the tower structural response, the frequency of the corresponding tower mode shapes was changed by $\pm 15 \%$ of $0.32 \mathrm{~Hz}$ by uniformly scaling the associated stiffness. Although tower stiffness is specified as a factor by which mode shapes are scaled, the drivetrain stiffness is entered directly. Note that the mode shapes themselves (which are specified independently of the mass and stiffness in ElastoDyn) were not changed in this process. The tower mass was changed by varying the distributed tower mass den- sity factor. The tower CM location was changed by varying the tower-base and -top density such that density increased at one end and decreased at the other (with a linear scaling variation in between) without changing the overall blade mass. The drivetrain damping term represents the combined effect of structural damping and drivetrain damping from active control not directly accounted for in the baseline controller of the NREL $5 \mathrm{MW}$ turbine.

\section{Blade structural properties}

For the blade structural properties, nine parameters were considered, including blade flapwise and edgewise stiffness (including stiffness imbalance), mass (including mass imbalance), CM, damping, and precone angle, as detailed in Table 8 . Through ElastoDyn, blade structural dynamics are modeled using two flapwise mode shapes and one edgewise mode shape per blade. To manipulate blade structural response, the frequency of the first flapwise and edgewise mode shapes was changed by $\pm 5 \%$ of 0.7 and $1 \mathrm{~Hz}$, respectively, by uniformly scaling the associated stiffness. The 
Table 6. Turbine aeroelastic parameters (39 total).

\begin{tabular}{|c|c|c|c|}
\hline $\begin{array}{l}\text { Support structure } \\
\text { properties }\end{array}$ & $\begin{array}{l}\text { Blade structural } \\
\text { properties }\end{array}$ & $\begin{array}{l}\text { Blade aerodynamic } \\
\text { properties }\end{array}$ & Controller properties \\
\hline Nacelle mass $\left(N_{\text {Mass }}\right)$ & $\begin{array}{l}\text { Blade flapwise stiffness } \\
\left(B_{\mathrm{FK}}\right)\end{array}$ & Twist $(\varnothing)$ at tip & Yaw angle error $(\theta)$ \\
\hline $\begin{array}{l}\text { Nacelle } \mathrm{CM} \\
x \text { location }\left(N_{\mathrm{CM}}\right)\end{array}$ & $\begin{array}{l}\text { Blade edgewise } \\
\text { stiffness }\left(B_{\mathrm{EK}}\right)\end{array}$ & Chord $(c)$ at root and tip & $\begin{array}{l}\text { Collective pitch } \\
\text { error }\left(\varnothing_{\text {err,coll }}\right)\end{array}$ \\
\hline Tower CM location $\left(T_{\mathrm{CM}}\right)$ & $\begin{array}{l}\text { Blade flapwise stiffness } \\
\text { imbalance }\left(B_{\mathrm{FK}, \mathrm{imb}}\right)\end{array}$ & $\begin{array}{l}\text { Leading-edge separation } \\
\text { time constant }\left(T_{f 0}\right)\end{array}$ & $\begin{array}{l}\text { Imbalanced pitch } \\
\text { error }\left(\emptyset_{\text {err,imb }}\right)\end{array}$ \\
\hline Tower stiffness $\left(T_{\mathrm{KF}}\right)$ & $\begin{array}{l}\text { Blade edgewise stiffness } \\
\text { imbalance }\left(B_{\mathrm{EK}, \mathrm{imb}}\right)\end{array}$ & $\begin{array}{l}\text { Vortex shedding time } \\
\text { constant }\left(T_{\mathrm{V} 0}\right)\end{array}$ & \\
\hline Tower mass $\left(T_{\mathrm{MD}}\right)$ & $\begin{array}{l}\text { Blade damping } \\
\text { ratio }\left(B_{\mathrm{DR}}\right)\end{array}$ & $\begin{array}{l}\text { Leading-edge pressure } \\
\text { gradient time constant }\left(T_{\mathrm{p}}\right)\end{array}$ & \\
\hline $\begin{array}{l}\text { Tower damping } \\
\text { ratio }\left(T_{\mathrm{DR}}\right)\end{array}$ & Blade mass $\left(B_{\mathrm{M}}\right)$ & $\begin{array}{l}\text { Vortex advection } \\
\text { time constant }\left(T_{\mathrm{VL}}\right)\end{array}$ & \\
\hline Drivetrain stiffness $\left(D_{\mathrm{K}}\right)$ & $\begin{array}{l}\text { Blade mass imbalance } \\
\left(B_{\mathrm{M}, \mathrm{imb}}\right)\end{array}$ & Strouhal number $\left(S t_{\mathrm{sh}}\right)$ & \\
\hline Drivetrain damping $\left(D_{\mathrm{D}}\right)$ & Blade CM location $\left(B_{\mathrm{CM}}\right)$ & Lift $\left(C_{1}\right)$ at root and tip & \\
\hline \multirow[t]{4}{*}{ Shaft angle $\left(\alpha_{\mathrm{S}}\right)$} & Precone $\left(\beta_{p}\right)$ & $\begin{array}{l}\text { TES Lift AoA }\left(\alpha_{\mathrm{TES}}\right) \\
\text { at root and tip }\end{array}$ & \\
\hline & & $\begin{array}{l}\text { Max Lift AoA }\left(\alpha_{\max }\right) \\
\text { at root and tip }\end{array}$ & \\
\hline & & $\begin{array}{l}\text { SR Lift AoA }\left(\alpha_{\mathrm{SR}}\right) \\
\text { at root and tip }\end{array}$ & \\
\hline & & $\begin{array}{l}0^{\circ} \text { drag }\left(C_{\mathrm{d}, 0}\right) \\
\text { at root and tip }\end{array}$ & \\
\hline
\end{tabular}

Table 7. Parameter value ranges of turbine support structure parameters.

\begin{tabular}{|c|c|c|c|c|c|c|c|c|c|}
\hline & $\begin{array}{r}N_{\text {mass }} \\
(\mathrm{kg})\end{array}$ & $\begin{array}{r}N_{\mathrm{CM}} \\
(\mathrm{m})\end{array}$ & $\begin{array}{r}T_{\mathrm{CM}} \\
(\mathrm{m})\end{array}$ & $\begin{array}{r}T_{\mathrm{KF}} \\
(-)\end{array}$ & $\begin{array}{r}T_{\mathrm{MD}} \\
(-)\end{array}$ & $\begin{array}{r}T_{\mathrm{DR}} \\
(\%)\end{array}$ & $\begin{array}{r}D_{\mathrm{K}} \\
(\mathrm{N} \cdot \mathrm{m})\left(\mathrm{rad}^{-1}\right)\end{array}$ & $\begin{array}{r}D_{\mathrm{D}} \\
(\mathrm{N} \cdot \mathrm{m})\left(\operatorname{rad~s}^{-1}\right)^{-1}\end{array}$ & $\begin{array}{l}\alpha_{\mathrm{S}} \\
\left(^{\circ}\right)\end{array}$ \\
\hline Nom. & 240000 & 1.9 & 42.505 & 1.02 & 1 & 2.55 & 867637000 & 6215000 & -5 \\
\hline Min. & 216000 & 1.71 & 40.38 & 0.72 & 0.95 & 0.1 & 780873300 & 0.0 & -5.2 \\
\hline Max. & 264000 & 2.09 & 44.63 & 1.32 & 1.05 & 5.0 & 954400700 & 12430000 & -4.8 \\
\hline Ref. & $\begin{array}{r}\text { Witcher } \\
(2017)\end{array}$ & Exp. & Exp. & $\begin{array}{r}\text { Koukoura } \\
(2014)\end{array}$ & $\begin{array}{r}\text { Witcher } \\
(2017)\end{array}$ & $\begin{array}{r}\text { Koukoura } \\
(2014)\end{array}$ & $\begin{array}{r}\text { Holierhoek } \\
\text { et al. } \\
(2010)\end{array}$ & $\begin{array}{r}\text { Holierhoek } \\
\text { et al. } \\
(2010)\end{array}$ & $\begin{array}{r}\text { Santos and } \\
\text { van Dam } \\
(2015)\end{array}$ \\
\hline
\end{tabular}

blade mass was changed by uniformly scaling the distributed blade mass of all blades. The nominal scaling of 1.04536 is described in the NREL $5 \mathrm{MW}$ specifications document (Jonkman et al., 2009). The blade CM location was changed by varying the blade root and tip density such that density increased at one end and decreased at the other with a linear scaling variation in between, without changing the overall blade mass. Blade imbalance effects were also included by varying the mass of each blade. The imbalances were introduced by applying a different change value to each blade.
Specifically, one blade was modified to be a value that is higher than the nominal value, and another was modified to a lower value. The third blade remained unchanged at the nominal value.

\section{Blade aerodynamic properties}

The blade aerodynamic properties were represented using 18 parameters: 3 associated with the blade twist and chord distribution; 10 associated with the static aerodynamic compo- 
Table 8. Parameter value ranges of turbine blade structure parameters.

\begin{tabular}{|c|c|c|c|c|c|c|c|c|c|}
\hline & $B_{\mathrm{FK}}(-)$ & $B_{\mathrm{EK}}(-)$ & $B_{\mathrm{FK}, \mathrm{imb}}(-)$ & $B_{\mathrm{EK}, \mathrm{imb}}(-)$ & $B_{\mathrm{DR}}\left(\%_{\text {critical }}\right)$ & $B_{\mathrm{M}}(-)$ & $B_{\mathrm{M}, \mathrm{imb}}(-)$ & $B_{\mathrm{CM}}(\mathrm{m})$ & $\beta_{\mathrm{p}}\left(^{\circ}\right)$ \\
\hline Nom. & 1 & 1 & 0.01 & 0.01 & 1.55 & 1.04536 & 0.025 & 0.015 & -2.5 \\
\hline Min. & 0.9 & 0.9 & 0.0 & 0.0 & 0.1 & 0.993 & 0.0 & 20.60 & -2.75 \\
\hline Max. & 1.1 & 1.1 & 0.02 & 0.02 & 3.0 & 1.1 & 0.05 & 22.60 & -2.25 \\
\hline Ref. & Exp. & Exp. & Exp. & Exp. & Exp. & $\begin{array}{r}\text { Witcher } \\
(2017)\end{array}$ & Exp. & $\begin{array}{r}\text { IEC } \\
(2010)\end{array}$ & Exp \\
\hline
\end{tabular}

nent; and 5 associated with the unsteady aerodynamic properties. Blade twist and chord distributions were manipulated by specifying a change in the distributions along the blade. Three parameters were defined, associated with changing the chord at the blade tip and root and twist at the blade tip. For each of these parameters, the associated distribution along the blade was modified linearly such that there was zero change at the opposite end. The root twist was not changed because the blade-pitch angle uncertainties are considered in the controller parameter section.

\section{Steady airfoil aerodynamics}

For the steady aerodynamic component, the lift and drag versus angle-of-attack (AoA) curves were modified to examine the sensitivity on resulting loads throughout the wind turbine. The turbine operated in normal operating conditions, and therefore only relevant regions of the curves were modified. The curves modified by parameterization using an approach based on one introduced by Abdallah et al. (2015). The approach used here parameterized the $C_{1}$ and $C_{\mathrm{d}}$ curves using five points; these points were perturbed and a spline fit to the points. The points of interest are

- beginning of linear $C_{1}$ region - determines the lower limit of the AoA range of interest and was kept constant $\left(\alpha_{\text {lin }}, C_{1, \text { lin }}\right)$;

- $C_{\mathrm{d}}$ value at $\mathrm{AoA}=0^{\circ}\left(0^{\circ}, C_{\mathrm{d}, 0}\right)$;

- trailing edge separation (TES) point - AoA location at which $C_{1}$ curve is no longer linear $\left(\alpha_{\mathrm{TES}}, C_{\mathrm{l}, \mathrm{TES}}\right)$;

- maximum $(\max )$ point - AoA location at which $C_{1}$ reaches a maximum $\left(\alpha_{\max }, C_{1, \max }\right)$;

- separation reattachment (SR) point - AoA location at which slope of $C_{1}$ curve is no longer negative $\left(\alpha_{\mathrm{SR}}, C_{1, \mathrm{SR}}\right)$.

The selected points of interest are similar to those selected by Abdallah et al. (2015). A notable difference is the consideration of $C_{\mathrm{d}, 0}$ as opposed to $C_{\mathrm{d}, 90}$, which is the $C_{\mathrm{d}}$ value at $\alpha=90^{\circ} ; C_{\mathrm{d}, 0}$ was chosen for this study because of the focus on normal operational region, as opposed to the extreme conditions considered by Abdallah et al. (2015). The

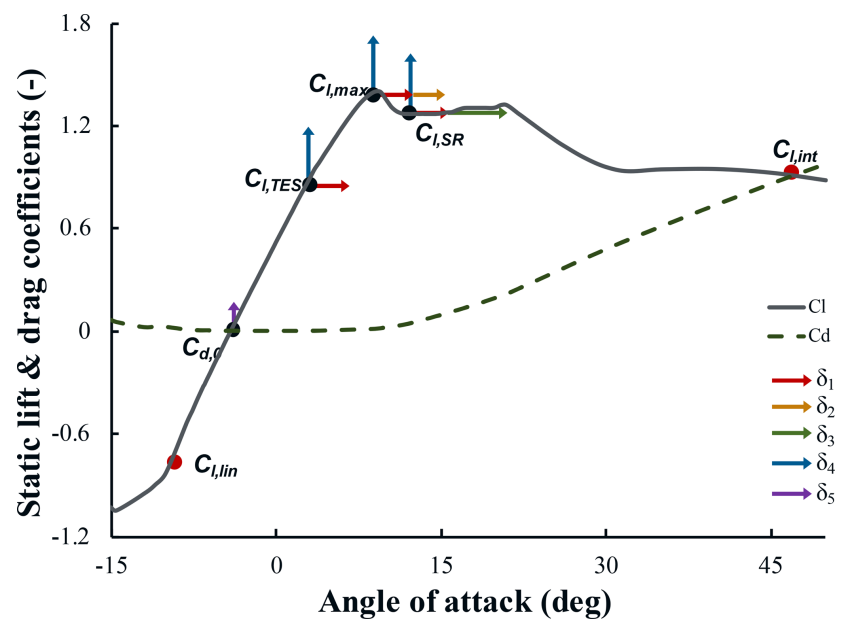

Figure 9. Perturbation of points of interest in representative $C_{1}$ and $C_{\mathrm{d}}$ curves.

three variable points of interest were perturbed by a percentage of the default value. The perturbations and correlations are depicted in Fig. 9 and parameter ranges are detailed in Table 9. From Abdallah et al. (2015), the TES, max, and SR $C_{1}$ values for an individual airfoil have a correlation to one another of 0.9 . Thus, all $C_{1}$ values are perturbed collectively, using the same percentage $\left(\delta_{4}\right)$. The AoA values are less correlated and are therefore perturbed independently of one another. However, to ensure that nonphysical relative values are not reached, all AoA values are perturbed by the same base percentage $\left(\delta_{1}\right)$, and then an additional independent variation of a smaller value was added $\left(\delta_{2}\right.$ and $\left.\delta_{3}\right)$ for $\alpha_{\max }$ and $\alpha_{\mathrm{SR}}$, respectively. The $C_{\mathrm{d}, 0}$ value was also perturbed $\left(\delta_{5}\right)$.

$C_{1}$ and $C_{\mathrm{d}}$ curves were altered for each airfoil. However, instead of specifying $\delta$ values for each airfoil, these values were specified at the root and tip airfoils, excluding the cylindrical airfoils at the base, which were not modified. Perturbation values for the interior airfoils were computed from a linear fit of the end point values. The method of developing the new curves for each airfoil is detailed here: 
Table 9. Parameter value ranges of turbine blade aerodynamic parameters.

\begin{tabular}{|c|c|c|c|c|c|c|c|c|c|c|c|c|c|}
\hline & $\phi_{\text {tip }}\left({ }^{\circ}\right)$ & $c_{\mathrm{r}}(\mathrm{m})$ & $c_{\mathrm{t}}(\mathrm{m})$ & $T_{\mathrm{f} 0}(-)$ & $T_{\mathrm{V} 0}(-)$ & $T_{\mathrm{p}}(-)$ & $T_{\mathrm{VL}}(-)$ & $S t_{\mathrm{sh}}(-)$ & $C_{1, \operatorname{tr}}(-)$ & $\alpha_{\mathrm{TES}, \operatorname{tr}}\left({ }^{\circ}\right)$ & $\alpha_{\max , \operatorname{tr}}\left({ }^{\circ}\right)$ & $\alpha_{\mathrm{SR}, \mathrm{tr}}\left({ }^{\circ}\right)$ & $C_{\mathrm{d}, 0, \operatorname{tr}}(-)$ \\
\hline Nom. & 0.106 & 3.542 & 1.419 & 6.5 & 8 & 1.35 & 16.5 & 0.245 & Var. & Var. & Var. & Var. & Var. \\
\hline Min. & -1.894 & 3.1878 & 1.2771 & 3 & 1 & 1 & 11 & 0.19 & $-26 \%$ & $-20 \%$ & $-8 \%$ & $-15 \%$ & $-100 \%$ \\
\hline Max. & 2.106 & 3.8962 & 1.5609 & 10 & 15 & 1.7 & 22 & 0.3 & $+26 \%$ & $+20 \%$ & $+8 \%$ & $+15 \%$ & $+100 \%$ \\
\hline Ref. & $\begin{array}{c}\text { Petrone } \\
\text { et al. } \\
(2011)\end{array}$ & $\begin{array}{r}\text { Loeven } \\
\text { and Bijl } \\
(2008)\end{array}$ & $\begin{array}{r}\text { Loeven } \\
\text { and Bijl } \\
(2008)\end{array}$ & $\begin{array}{c}\text { Damiani } \\
\text { et al. } \\
(2016)\end{array}$ & $\begin{array}{r}\text { Damiani } \\
\text { et al. } \\
(2016)\end{array}$ & $\begin{array}{r}\text { Damiani } \\
\text { et al. } \\
(2016)\end{array}$ & $\begin{array}{r}\text { Damiani } \\
\text { et al. } \\
(2016)\end{array}$ & $\begin{array}{c}\text { Damiani } \\
\text { et al. } \\
(2016)\end{array}$ & $\begin{array}{r}\text { Abdallah } \\
\text { et al. } \\
(2015)\end{array}$ & $\begin{array}{r}\text { Abdallah } \\
\text { et al. } \\
(2015)\end{array}$ & $\begin{array}{r}\text { Abdallah } \\
\text { et al. } \\
(2015)\end{array}$ & $\begin{array}{r}\text { Abdallah } \\
\text { et al. } \\
(2015)\end{array}$ & $\begin{array}{r}\text { Ehrmann } \\
\text { et al. } \\
(2017)\end{array}$ \\
\hline
\end{tabular}

1. AoA deltas are applied to the original AoA values via the following equations.

$$
\begin{aligned}
& \alpha_{\mathrm{TES}, \text { new }}=\alpha_{\mathrm{TES}, \text { orig }}+\alpha_{\mathrm{TES}, \text { orig }} \delta_{1}, \\
& \alpha_{\text {max,new }}=\alpha_{\mathrm{max}, \text { orig }}+\alpha_{\mathrm{max}, \text { orig }}\left(\delta_{1}+\delta_{2}\right), \\
& \alpha_{\mathrm{SR} \text {,new }}=\alpha_{\mathrm{SR}, \text { orig }}+\alpha_{\mathrm{SR}, \text { orig }}\left(\delta_{1}+\delta_{3}\right) .
\end{aligned}
$$

2. The new AoA values are fit to the nearest existing AoA value on the curve. The AoA resolution is fine enough that all perturbations are captured, though not precisely. This approach may need to be adjusted if the perturbations were to decrease.

3. For all new AoA values, the change in $C_{1}$ between the original $C_{1}$ value $\left(C_{1, T E S}\right)$ and the $C_{1}$ curve value at the new $\operatorname{AoA}\left(C_{1, \text { orig+ }}\right)$ is computed via

$\epsilon=C_{1, \text { orig }+}-C_{1, \text { orig }}$.

4. The total change in $C_{1}$ is then computed via

$C_{\mathrm{l}, \mathrm{diff}}=\delta_{4} C_{\mathrm{l}, \mathrm{orig}}-\epsilon$.

This ensures that if $\delta_{4}=0$, the final $C_{1, \text { new }}$ value is equivalent to that of the original curve.

5. For $C_{1}$ perturbation, the end points are located at the AoA associated with the beginning of the linear $C_{1}$ region $\left(C_{1, \text { lin }}\right)$ and $\alpha=90^{\circ}$; as these are fixed points, they have $C_{1, \text { diff }}=0$. The $C_{1}$ curve is replaced by a line between $\left(\alpha_{\text {lin }}, C_{1, \text { lin }}\right)$ and $\left(\alpha_{\mathrm{TES}}, \delta_{4} C_{1, \text { lin }}\right)$. A piece-wise linear spline - representing perturbations about the original curve - is constructed between the points ( $\alpha_{\text {TES, new }}$, $\left.\delta_{4} C_{1, \mathrm{TES}}\right),\left(\alpha_{\text {max,new }}, \delta_{4}, C_{1, \text { max }}\right),\left(\alpha_{\mathrm{SR}, \mathrm{new}}, \delta_{4}, C_{\mathrm{l}, \mathrm{SR}}\right)$, and $\left(90^{\circ}, 0\right)$.

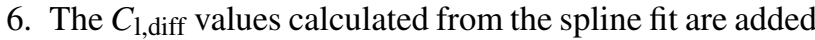
to the original $C_{1}$ curve via

$$
C_{1, \text { new }}=C_{1, \text { orig }+}+C_{1, \text { diff }} \text {. }
$$

A similar process was followed by modifying the $C_{\mathrm{d}}$ curves, wherein the $C_{\mathrm{d}}$ value corresponding to $\alpha=0^{\circ}\left(C_{\mathrm{d}, 0}\right)$ is perturbed by a specified value $\left(\delta_{5}\right)$ in the same manner as the $C_{1}$ values. A piece-wise linear spline is then fit between $\left(-90^{\circ}, C_{\mathrm{d},-90}\right),\left(0^{\circ}, C_{\mathrm{d}, 0}\right)$, and $\left(90^{\circ}, C_{\mathrm{d}, 90}\right)$ and added
Table 10. Parameter value ranges of turbine controller parameters.

\begin{tabular}{lrrr}
\hline & $\theta\left(^{\circ}\right)$ & $\emptyset_{\text {err,coll }}\left(^{\circ}\right)$ & $\emptyset_{\text {err,imb }}\left(^{\circ}\right)$ \\
\hline Nom. & 0 & 0 & 0.1 \\
Min. & -20 & -0.2 & 0 \\
Max. & 20 & 0.2 & 0.2 \\
Ref. & Quick et al. & Simms et al. & Simms et al. \\
& $(2017)$ & $(2001)$ & $(2001)$ \\
\hline
\end{tabular}

to the original $C_{\mathrm{d}}$ curve. $C_{\mathrm{d}, 0}$ is constrained to not go below 0 . Several modified $C_{1}$ and $C_{\mathrm{d}}$ curves for each airfoil section are shown in Fig. 10. Note that $C_{\mathrm{d}}$ curves are perturbed, but by a very small amount not visible in the plots. These perturbations result in modified $C_{1}$ and $C_{\mathrm{d}}$ curves that maintain the primary characteristics of the original curve, but differ in both magnitude and feature location.

\section{Unsteady airfoil aerodynamics}

There are several unsteady airfoil aerodynamic parameters that can be modified in OpenFAST. By expert opinion (Rick Damiani, personal communication, May 2018), several of these parameters have been identified as having the largest potential variability or impact on turbine response and are therefore included in this study. Several of the parameters in the Beddoes-Leishman-type unsteady airfoil aerodynamics model used here are derivable from the (perturbed) static lift and drag polars, i.e., when the lift and drag polars are perturbed, the associated Beddoes-Leishman unsteady airfoil aerodynamic parameters are perturbed as well. Additionally, there are several other parameters associated with unsteady aerodynamics that are included in OpenFAST. These parameters are

- $T_{\mathrm{f} 0}$ - time constant connected to leading-edge separation of the airfoil,

- $T_{\mathrm{V} 0}-$ time constant connected to vortex shedding,

- $T_{\mathrm{p}}$ - time constant connected to the leading-edge pressure gradient,

- $T_{\mathrm{VL}}$ - time constant connected to the vortex advection process, 

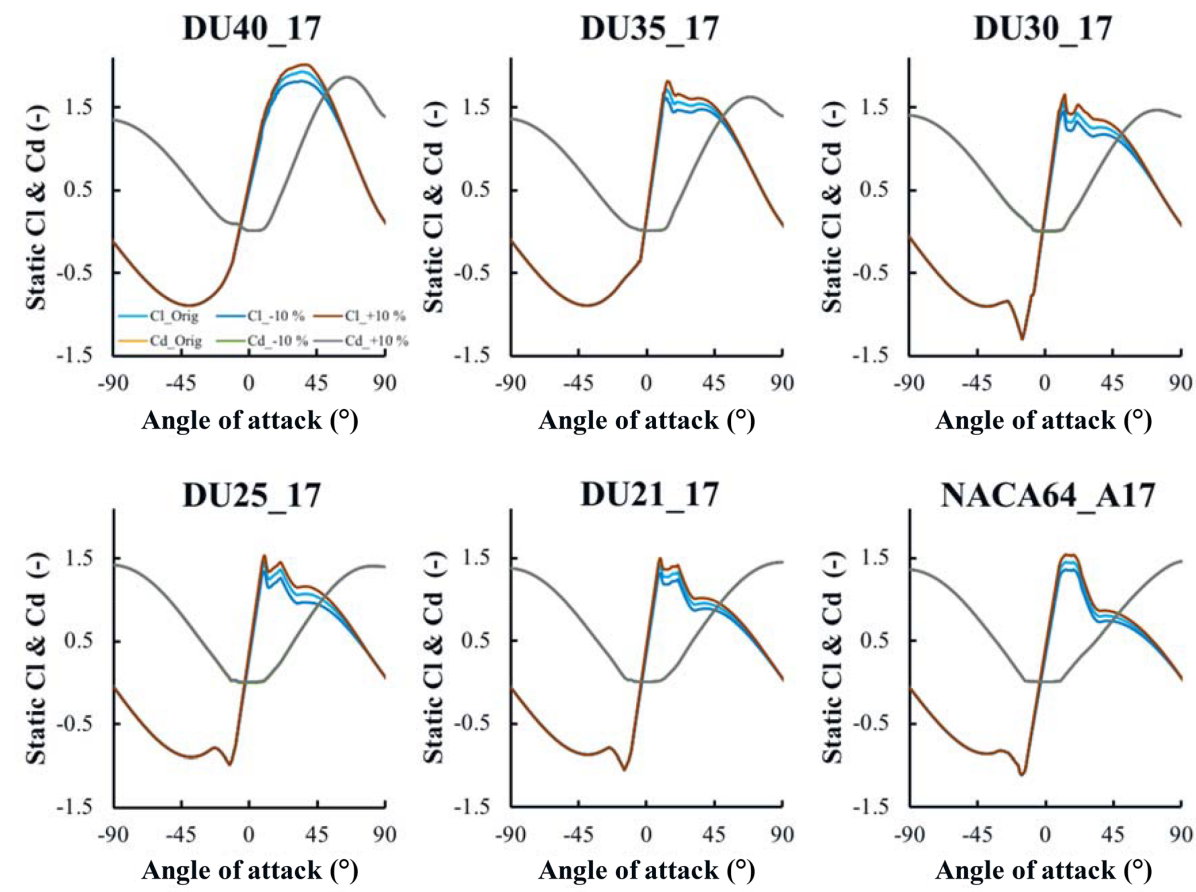

Figure 10. Sample original and perturbed $C_{1}$ and $C_{\mathrm{d}}$ curves for each airfoil section used in the NREL 5 MW reference turbine. Perturbed values represent $\pm 10 \%$ of the specified range for each parameter.

Table 11. Percentage of contribution to total number of significant events for ultimate and fatigue loads.

\begin{tabular}{lrrrrrrrrrrrrrrr}
\hline & $\begin{array}{r}\theta \\
\left({ }^{\circ}\right)\end{array}$ & $\begin{array}{r}B_{\mathrm{M}, \mathrm{imb}} \\
(-)\end{array}$ & $\begin{array}{r}C_{1, \mathrm{t}} \\
(-)\end{array}$ & $\begin{array}{r}\varnothing \\
\left({ }^{\circ}\right)\end{array}$ & $\begin{array}{r}B_{\mathrm{M}} \\
(-)\end{array}$ & $\begin{array}{r}C_{\mathbf{l , b}} \\
(-)\end{array}$ & $\begin{array}{r}\alpha_{\text {max,b }} \\
\left({ }^{\circ}\right)\end{array}$ & $\begin{array}{r}B_{\mathrm{CM}} \\
(-)\end{array}$ & $\begin{array}{r}B_{\mathrm{FK}} \\
(-)\end{array}$ & $\begin{array}{r}N_{\mathrm{CM}} \\
(\mathrm{m})\end{array}$ & $\begin{array}{r}N_{\text {mass }} \\
(\mathrm{kg})\end{array}$ & $\begin{array}{r}\alpha_{\mathrm{TES}, \mathrm{b}} \\
\left({ }^{\circ}\right)\end{array}$ & $\begin{array}{r}c_{\mathrm{b}} \\
(\mathrm{m})\end{array}$ & $\begin{array}{r}T_{\mathrm{KF}} \\
(\mathrm{m})\end{array}$ & $\begin{array}{r}D_{\mathrm{D}} \\
(\mathrm{m})\end{array}$ \\
\hline Ult. load (\%) & 21.5 & 8.8 & 21.9 & 12.7 & 2.5 & 9.2 & 4.0 & 0.6 & 3.6 & 3.0 & 2.9 & 0.8 & 1.9 & 0.2 & 1.3 \\
Fat. load (\%) & 23.7 & 21.2 & 17.4 & 8.8 & 10.4 & 6.7 & 1.9 & 3.7 & 0.3 & 0.0 & 0.6 & 1.9 & 0.6 & 1.7 & 1.4 \\
\hline
\end{tabular}

- $S t_{\mathrm{sh}}$ - Strouhal number associated with the vortex shedding frequency.

These quantities were varied over the ranges detailed in Table 9 and are constant across the blade.

\section{Controller properties}

Turbine yaw error was incorporated by directly changing the yaw angle of the turbine (see Table 10). For the collective blade pitch error, the twist distribution of each blade was identically shifted uniformly along the blade independent of the twist change in Table 9. For the imbalance pitch error, modified twist distributions were applied to two of the blades: one with a higher-than-nominal tip twist, one with a lower-than-nominal tip twist, and one unchanged.

\subsubsection{Elementary effects}

The EE value calculation and analysis process are the same as was used for the wind parameter analysis. Sixty wind file seeds $(S)$ were needed based on a convergence study of the ultimate and fatigue load metrics for all QoIs. This increase in the number of required wind file seeds compared with the inflow study is likely due to some turbine input parameter combinations causing resonance. Based on these numbers, the total number of simulations performed for the wind-inflow case study was $R \times(I+1) \times S \times B=$ $30 \times 40 \times 60 \times 3=216000$.

The EE values across all input parameters, input hyperspace points, and wind speed bins were examined for all QoIs for the ultimate and fatigue loads. For each QoI, the number of times an EE value exceeded the threshold for a given QoI was tallied. The resulting tallies are shown in Fig. 11, with the ultimate load tally on the top and fatigue load tally on the bottom. Note that nearly twice as many significant events were counted for fatigue loads; fewer significant events were counted for ultimate loads because of the limited threshold exceedance in the below-rated wind speeds. The percentage that each relevant input parameter contributed to the total significant event count is summarized in Table 11. Ultimate turbine loads are most sensitive to yaw error $(\theta)$ and $C_{1}$ distribution at the outboard section of the blade $\left(C_{1, t}\right)$, which, 
(a)

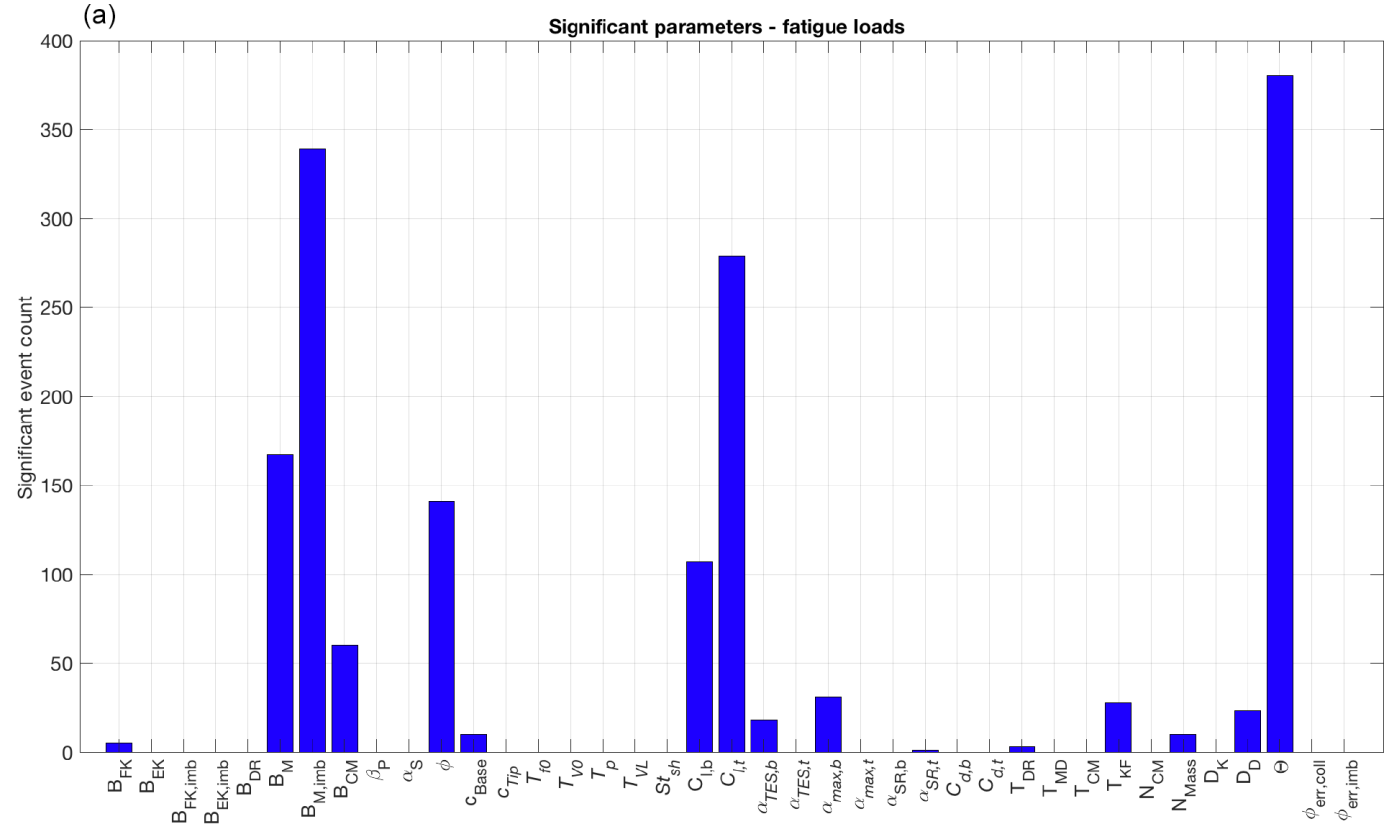

(b)

Significant parameters - ultimate loads

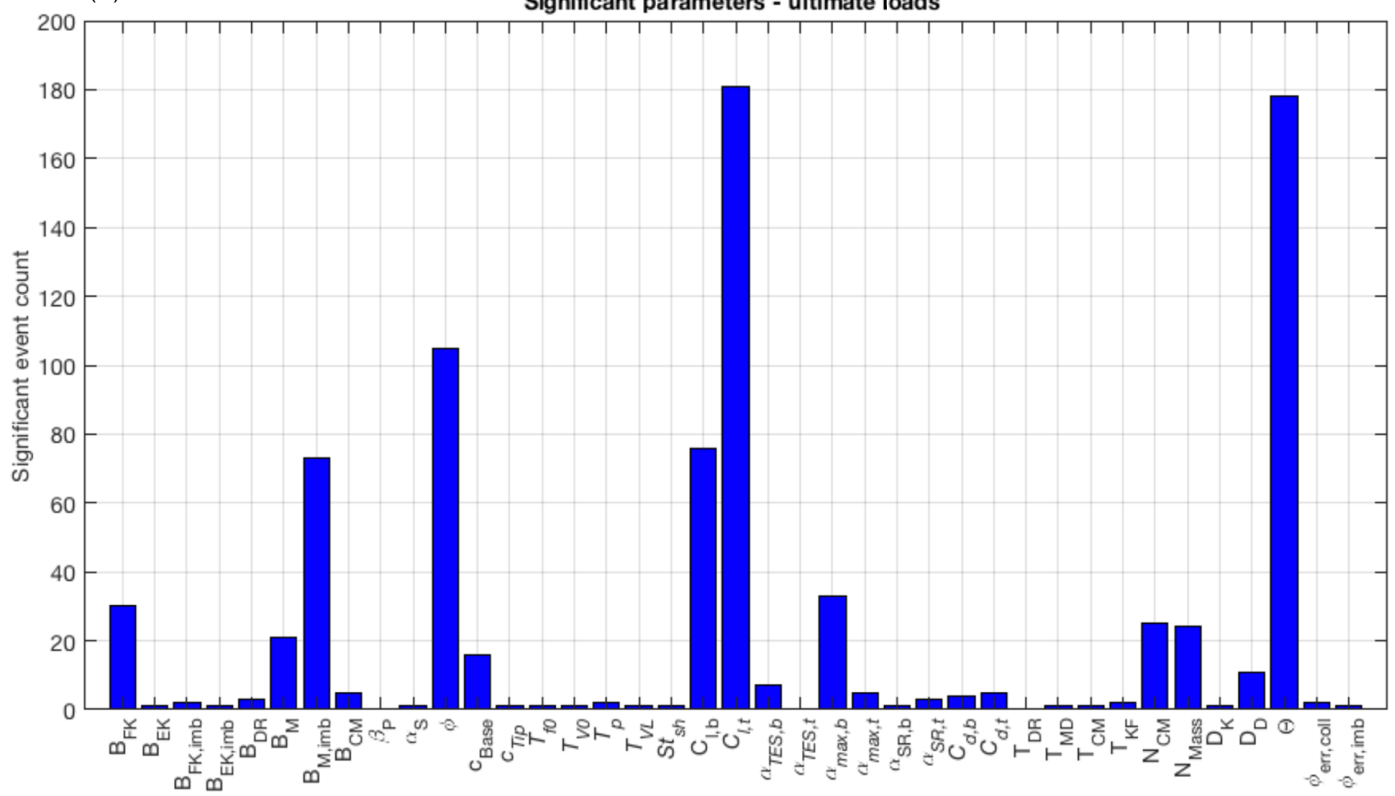

Figure 11. Identification of significant parameters using (a) ultimate and (b) fatigue loads. Significant events are defined by the number of outliers identified across each of the QoIs for all wind speed bins, input parameters, and simulation points.

when combined, accounted for nearly half of all significant events. Fatigue loads are also highly sensitive to blade mass imbalance $\left(B_{\mathrm{M}, \mathrm{imb}}\right)$. Turbine loads are also sensitive to twist distribution $(\varphi)$, blade mass $\left(B_{\mathrm{M}}\right)$, and the $C_{1}$ distribution at the inboard section of the blade $\left(C_{1, \mathrm{~b}}\right)$. Though these results are expected, their relative importance is likely a new finding. Other input parameters that were found to affect turbine load sensitivity are inboard maximum AoA $\left(\alpha_{\max , \mathrm{b}}\right)$, blade mass center of mass $\left(B_{\mathrm{CM}}\right)$, blade flapwise stiffness $\left(B_{\mathrm{FK}}\right)$, nacelle center of mass location $\left(N_{\mathrm{CM}}\right)$, nacelle mass $\left(N_{\text {mass }}\right)$, chord length at the inboard section of the blade $\left(c_{\mathrm{b}}\right)$, tower stiffness $\left(T_{\mathrm{KF}}\right)$, drivetrain damping $\left(D_{\mathrm{D}}\right)$, and inboard trailing edge separation AoA $\left(\alpha_{\mathrm{TES}, \mathrm{b}}\right)$. The AoA values at the inboard section of the blade are likely more important than at the outboard section due to the higher likelihood of the inboard section operating with higher AoA near stall. Additionally, the range of AoA values at the inboard section is larger than at the outboard section because the nominal inboard AoA values are higher, which could contribute to greater sensitivity. 
Blade-root bend. mom.

(kN-m)

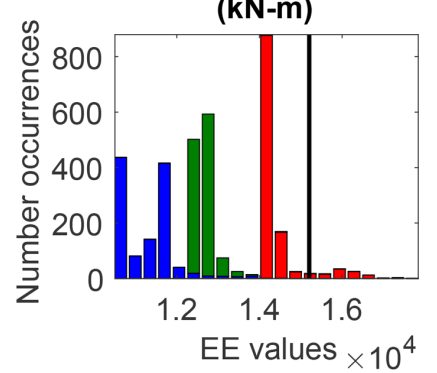

Rotor torque

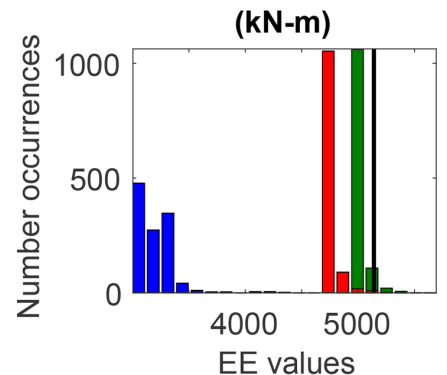

Tower-base bend. mom.

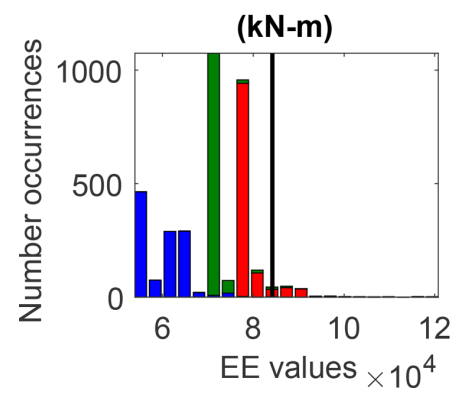

Blade-root pitch. mom.

$(\mathrm{kN}-\mathrm{m})$

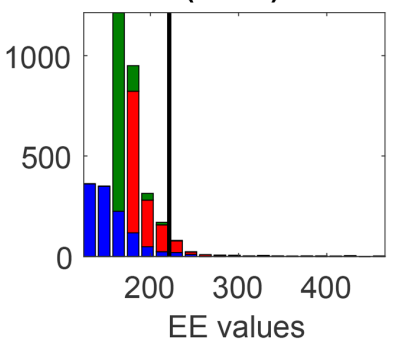

Tower-top bend. mom. (kN-m)

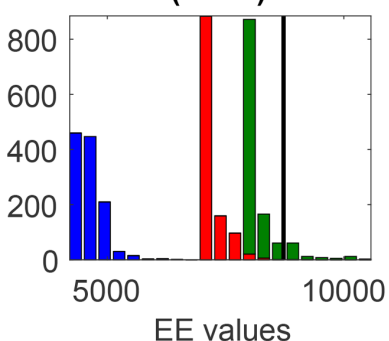

Blade OoP def.

(m)

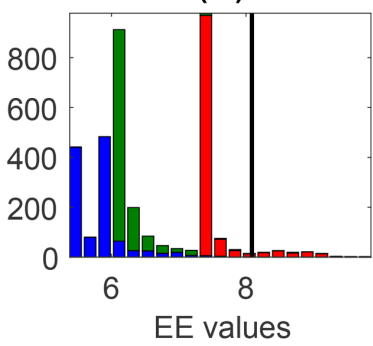

Main shaft bend. mom.

(kN-m)

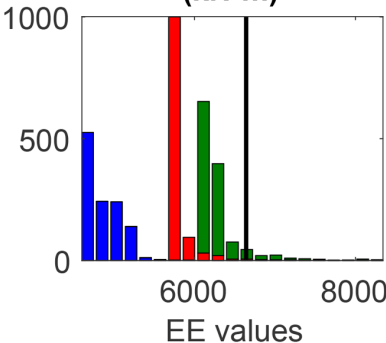

Tower-top yaw mom.

(kN-m)

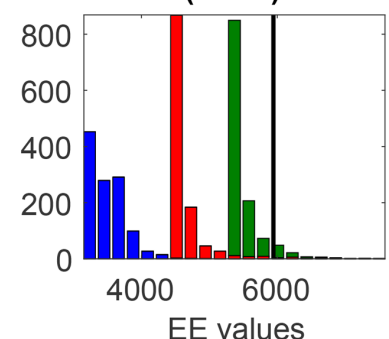

Electrical power

(kW)

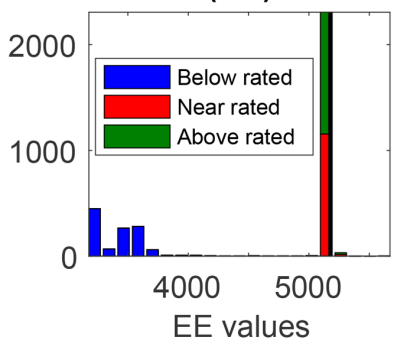

Figure 12. Stacked EE-value histograms of ultimate loads across all wind speed bins, input parameters, and simulation points for all QoIs. The black line represents the threshold by which outliers are counted for each QoI. Color indicates wind speed bin (blue is below-rated speed, red is near-rated speed, green is above-rated speed).

Histograms of the EE values for each of the QoIs are plotted in Figs. 12-15 for the ultimate and fatigue load metrics (associated exceedance probability plots are shown in Appendix B, Figs. B3 and B4). Here, EE values are colored by wind speed and the black vertical line represents the threshold for each QoI. The sharp separation of ultimate load EE values between wind speed bins is evident in Fig. 12 . A zoomed-in view of the lower count values is shown in Fig. 13. The more evenly distributed nature of the fatigue load EE values is further highlighted in the histogram plots depicted in Fig. 14 and zoomed-in views in Fig. 15. Unlike ultimate load EE values, all wind speed bins contribute to the outlier count for each QoI. Histogram plots of blade-root ultimate and fatigue bending moment $\mathrm{EE}$ values are shown in Figs. 16 and 17, respectively. The sharp separation of ultimate load EE values between wind speed bins is again evident. Highlighted in the fatigue load plots is the more even distribution of threshold-exceeding EE values across wind speed bins.

The grouping of the results by wind speed bin creates an unequal distribution of outliers resulting from each turbine QoI. Most notably, blade-root pitching moment accounts for $18 \%$ of the total ultimate load significant events, whereas rotor torque accounts for only $5 \%$. This suggests that it may be better to tailor the threshold for each QoI but this was deemed overly complicated for this first pass at assessing the sensitivity. Additionally, for a given QoI, it is typical for all ultimate load significant events to occur from either the nearor above-rated wind speeds. However, fatigue load EE values are more evenly distributed across wind speed bins, as shown in Fig. 14. The lower significant event counts for ultimate loads is a result of the segregated nature of the ultimate load EE values, as opposed to the more evenly distributed nature of the fatigue load EE values. In fact, unlike ultimate load EE values, a large percentage of significant events re- 

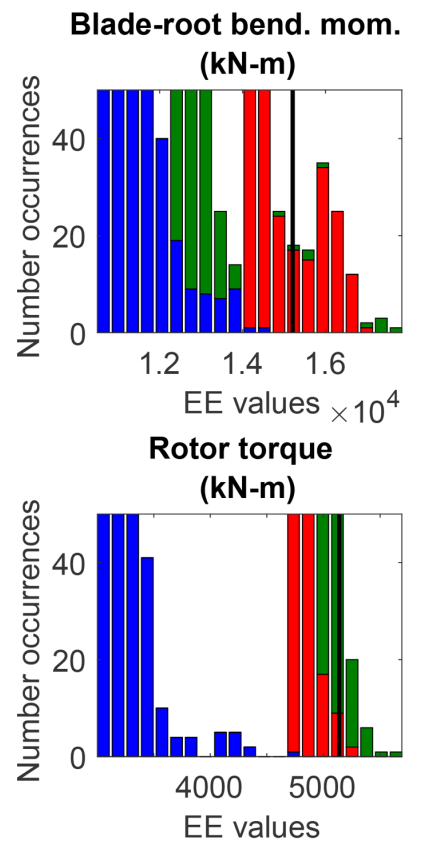

Tower-base bend. mom. (kN-m)

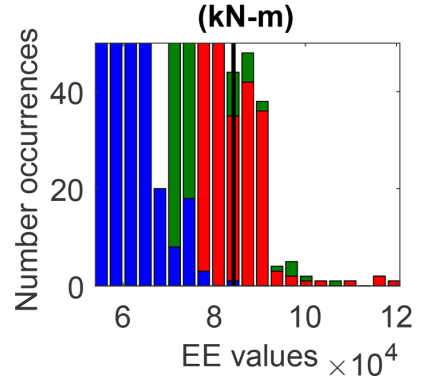

Blade-root pitch. mom.

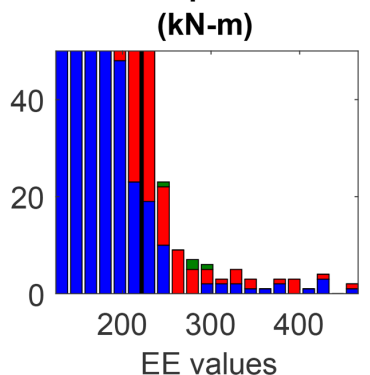

Tower-top bend. mom. (kN-m)

Main shaft bend. mom.

(kN-m)

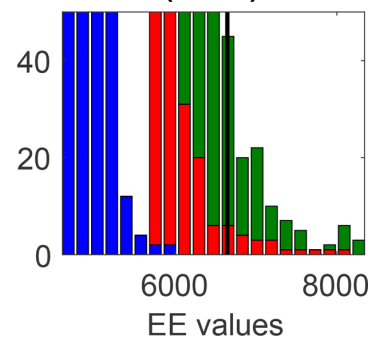

Tower-top yaw mom.

(kN-m)

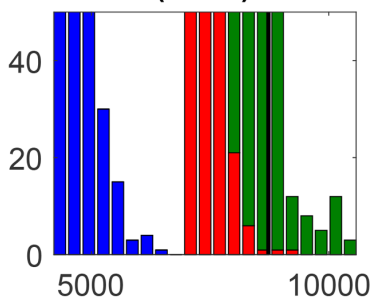

EE values

Blade OoP def.

(m)

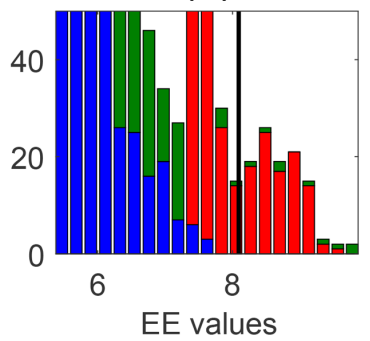

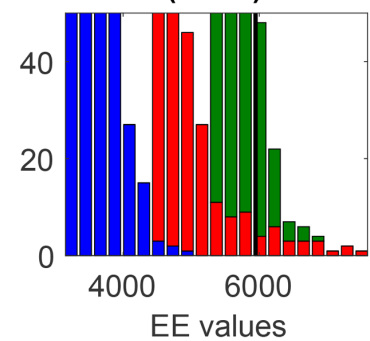

Electrical power (kW)

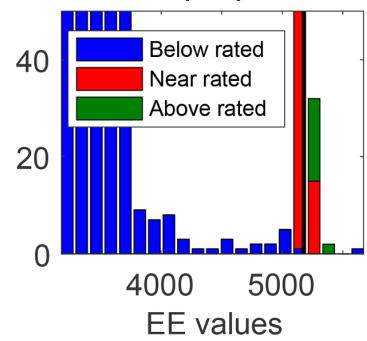

Figure 13. Zoomed-in stacked EE-value histograms of ultimate loads across all wind speed bins, input parameters, and simulation points for all QoIs. The black line represents the threshold by which outliers are counted for each QoI. Color indicates wind speed bin (blue is below-rated speed, red is near-rated speed, green is above-rated speed).

sult from below-rated wind speed cases because of the higher probability of low-wind-speed conditions. However, the distribution of fatigue load outliers resulting from each turbine QoI is approximately the same as the distribution for ultimate load outliers, with $14.6 \%$ of outliers resulting from the blade-root OoP bending moment and only $4.3 \%$ resulting from the blade-root pitching moment. Note that the QoI (blade-root pitching moment) that contributed the most outliers for ultimate load outliers contributes the least for fatigue load outliers.

The behavior of blade-root loads are examined in more detail by plotting exceedance probability distinctly for each input parameter in Fig. 18. Highlighted in these plots is the contribution of the individual input parameters to the outlier counts. For blade-root bending ultimate moment EE values, blade twist and $C_{1, \mathrm{t}}$ EE values in the near-rated wind speed bin are beyond the threshold for every point in the hyperspace. Yaw error and $C_{1, \mathrm{~b}} \mathrm{EE}$ values from the near-rated wind speed bin and yaw error from the above-rated wind speed bin also cross the threshold. For blade-root OoP bending fatigue moment EE values, the threshold is exceeded by blade twist and $C_{1, \mathrm{t}} \mathrm{EE}$ values from the below- and above-rated wind speeds for every point in the hyperspace. However, for all other relevant input parameters, only certain points in the hyperspace result in threshold exceedance. This indicates that, for certain loads and input parameters, the sensitivity of the turbine is dependent on the combination of turbine parameter values. These results can be used in future studies to more thoroughly investigate the hyperspace to determine how input parameter value combinations contribute to turbine sensitivity.

For each QoI, the number of times each input parameter contributed to the significant event count was tallied. The top parameters are shown in Tables 12 and 13 for ultimate and fatigue loads, respectively. Overall, $63 \%$ of the top sensitive parameters for both ultimate and fatigue loads are due to aerodynamic perturbations or yaw error. Blade-root and main shaft moments are especially sensitive to perturbations 

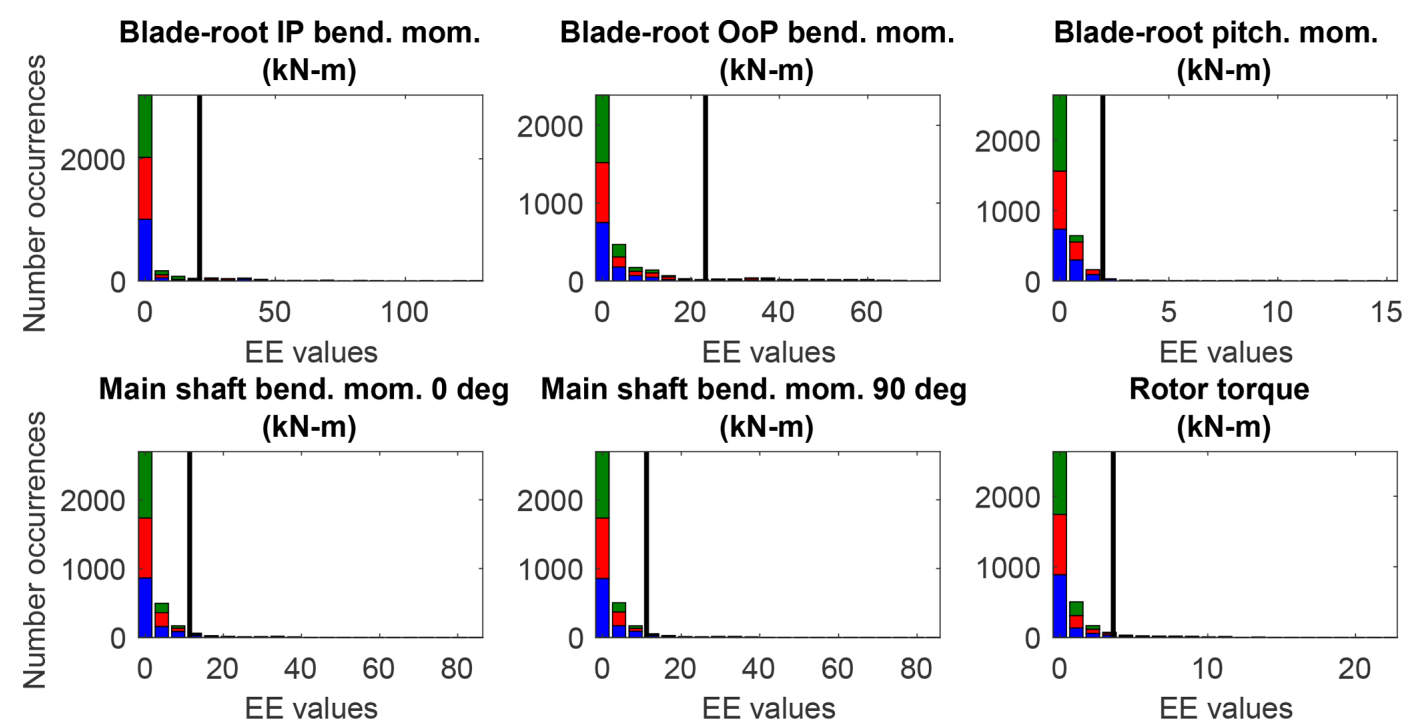

Main shaft bend. mom. 90 deg

Rotor torque
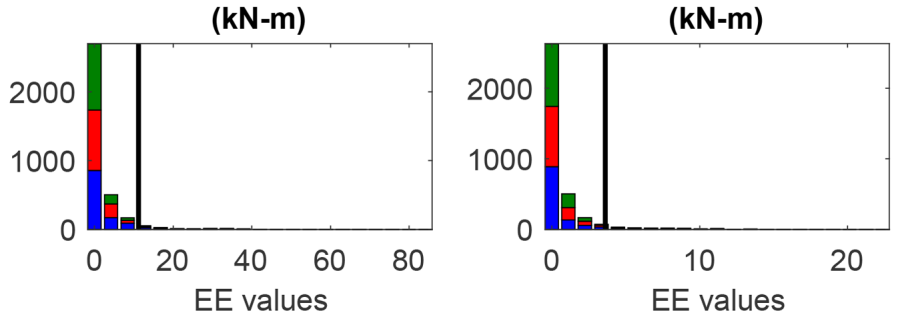

Tower-top FA bend. mom.

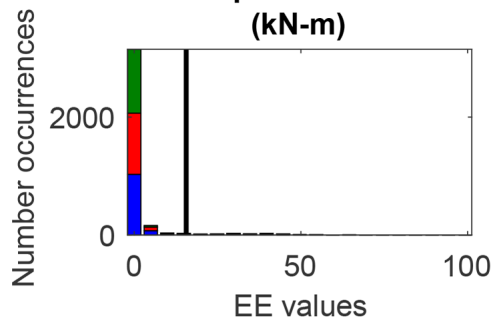

Tower-top SS bend. mom.

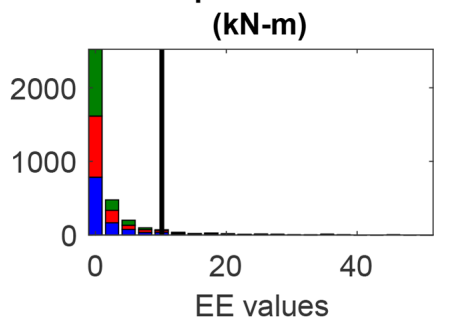

Tower-top yaw mom.

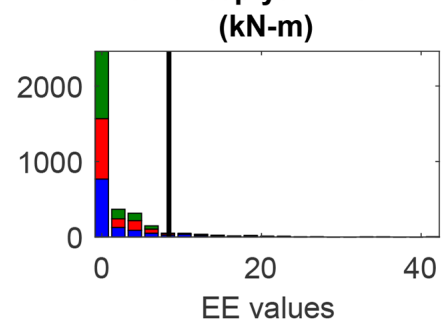

Tower-base FA bend. mom

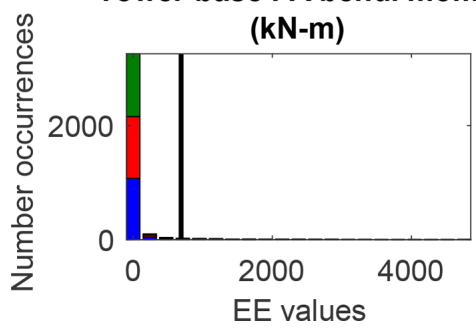

Tower-base SS bend. mom.

(kN-m)
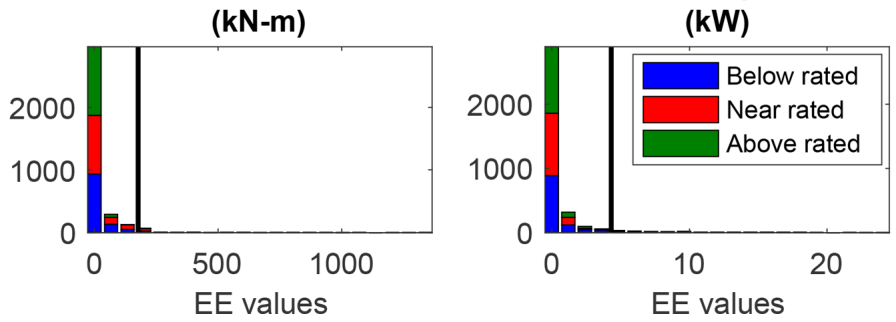

Figure 14. Stacked EE-value histograms of fatigue loads across all wind speed bins, input parameters, and simulation points for all QoIs. The black line represents the threshold by which outliers are counted for each QoI. Color indicates wind speed bin (blue is below-rated speed, red is near-rated speed, green is above-rated speed).

Table 12. Primary input parameters contributing to ultimate load sensitivity of each QoI. Values indicate how many times the variable contributes to the sensitivity count.

\begin{tabular}{rrrrrrrr}
\hline $\begin{array}{r}\text { Blade-root } \\
\text { bend. mom. }\end{array}$ & $\begin{array}{r}\text { Blade-root } \\
\text { pitch. mom. }\end{array}$ & $\begin{array}{r}\text { Main shaft } \\
\text { bend. mom. }\end{array}$ & $\begin{array}{r}\text { Rotor } \\
\text { torque }\end{array}$ & $\begin{array}{r}\text { Tower-top } \\
\text { bend. mom. }\end{array}$ & $\begin{array}{r}\text { Tower-top } \\
\text { yaw mom. }\end{array}$ & $\begin{array}{r}\text { Tower-base } \\
\text { bend. mom. }\end{array}$ & $\begin{array}{r}\text { Blade OoP } \\
\text { deflection }\end{array}$ \\
\hline$\theta(39)$ & $\alpha_{\text {max,b }}(33)$ & $\theta(43)$ & $B_{\mathrm{M}, \text { imb }}(26)$ & $\theta(28)$ & $C_{1, \mathrm{t}}(28)$ & $\varphi / C_{1, \mathrm{t}}(30)$ & $\varphi / C_{\mathrm{l}, \mathrm{b}}(30)$ \\
\hline$\varphi / C_{1, \mathrm{t}}(30)$ & $C_{\mathrm{l}, \mathrm{b}}(15)$ & $C_{\mathrm{l}, \mathrm{t}}(37)$ & $D_{\mathrm{D}}(25)$ & $N_{\mathrm{M}}(19)$ & $\theta(25)$ & $C_{\mathrm{l}, \mathrm{b}}(28)$ & $B_{\mathrm{FK}}(28)$ \\
\hline$C_{1, \mathrm{~b}}(7)$ & $\varphi(14)$ & $c_{\mathrm{b}}(22)$ & $B_{\mathrm{M}}(17)$ & $N_{\mathrm{CM}} / C_{1, \mathrm{t}}(17)$ & $C_{1, \mathrm{~b}}(21)$ & $B_{\mathrm{M}, \mathrm{imb}}(27)$ & $\theta(27)$ \\
\hline
\end{tabular}



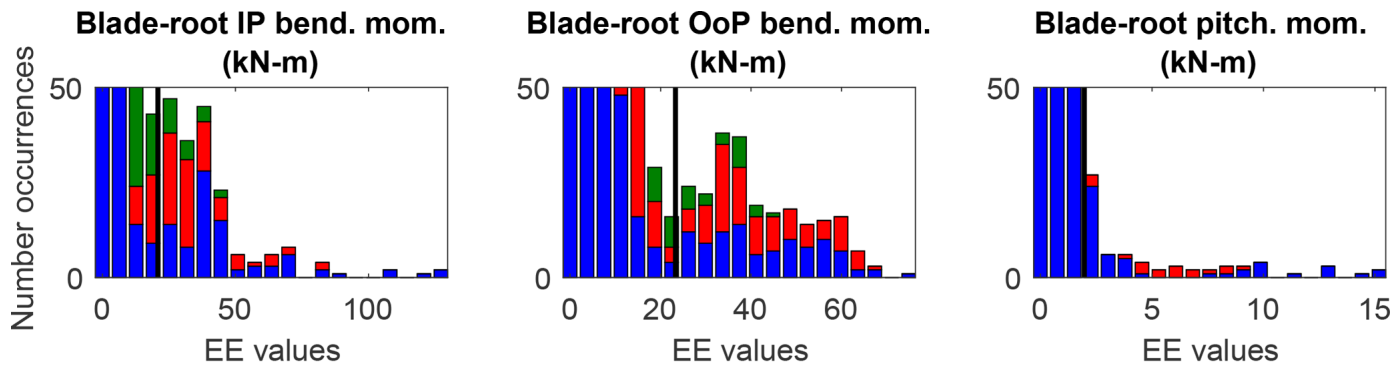

Main shaft bend. mom. 0 deg Main shaft bend. mom. 90 deg
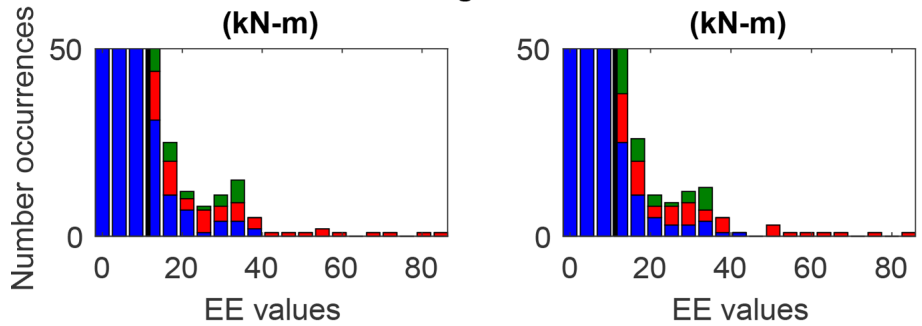

Rotor torque

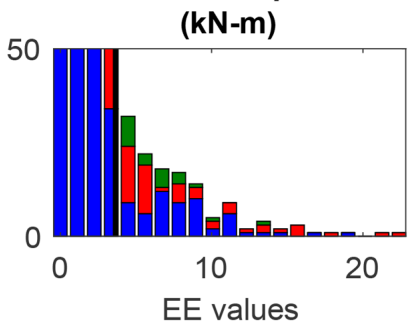

Tower-top FA bend. mom.

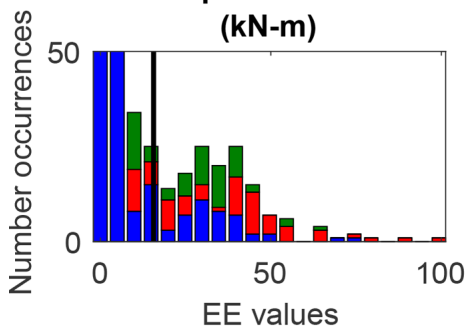

Tower-top SS bend. mom.

Tower-top yaw mom.
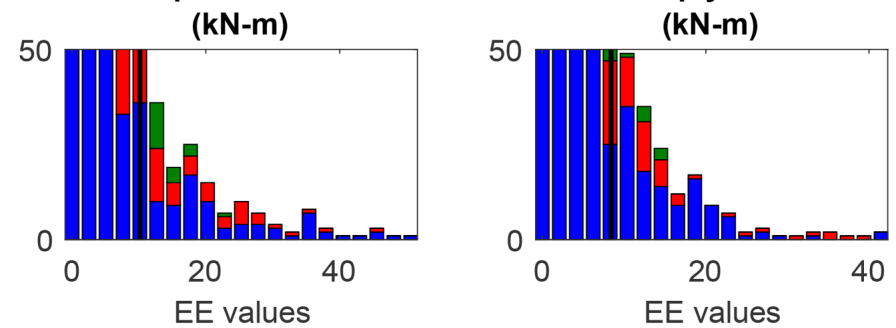

Tower-base FA bend. mom. Tower-base SS bend. mom.
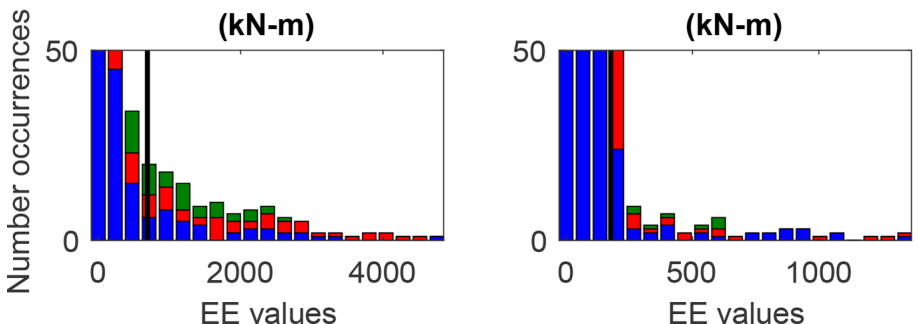

Electrical power $(\mathrm{kW})$

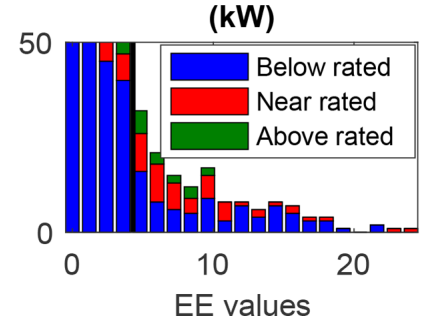

Figure 15. Zoomed-in stacked EE-value histograms of fatigue loads across all wind speed bins, input parameters, and simulation points for all QoIs. The black line represents the threshold by which outliers are counted for each QoI. Color indicates wind speed bin (blue is below-rated speed, red is near-rated speed, green is above-rated speed).

Table 13. Primary input parameters contributing to fatigue load sensitivity of each QoI. Values indicate how many times the variable contributes to the sensitivity count.

\begin{tabular}{|c|c|c|c|c|c|c|c|c|c|c|}
\hline $\begin{array}{l}\text { Blade-root } \\
\text { IP bend. } \\
\text { moment }\end{array}$ & $\begin{array}{r}\text { Blade-root } \\
\text { OoP pitch. } \\
\text { moment }\end{array}$ & $\begin{array}{r}\text { Blade-root } \\
\text { pitch. } \\
\text { moment }\end{array}$ & $\begin{array}{r}\text { Main shaft } \\
\text { bending } \\
\text { moment } 0^{\circ}\end{array}$ & $\begin{array}{r}\text { Main shaft } \\
\text { bending } \\
\text { mom. } 90^{\circ}\end{array}$ & $\begin{array}{l}\text { Rotor } \\
\text { torque }\end{array}$ & $\begin{array}{r}\text { Tower-top } \\
\text { FA bend. } \\
\text { moment }\end{array}$ & $\begin{array}{c}\text { Tower-top } \\
\text { SS bend. } \\
\text { moment }\end{array}$ & $\begin{array}{r}\text { Tower-top } \\
\text { yaw } \\
\text { moment }\end{array}$ & $\begin{array}{c}\text { Tower-base } \\
\text { FA bend. } \\
\text { moment }\end{array}$ & $\begin{array}{r}\text { Tower-base } \\
\text { SS bend. } \\
\text { moment }\end{array}$ \\
\hline$B_{\mathrm{CM}}(59)$ & $\varphi / C_{1, \mathrm{t}}(60)$ & $\alpha_{\max , \mathrm{b}}(31)$ & $\theta(49)$ & $\theta(49)$ & $B_{\mathrm{M}, \mathrm{imb}}(51)$ & $\theta(75)$ & $\theta(64)$ & $C_{\mathrm{l}, \mathrm{t}}(59)$ & $B_{\mathrm{M}, \mathrm{imb}}(59)$ & $T_{\mathrm{KF}}(28)$ \\
\hline$B_{\mathrm{M}, \mathrm{imb}}(52)$ & $C_{1, \mathrm{~b}}(54)$ & $\alpha_{\mathrm{TES}, \mathrm{b}}(18)$ & $C_{1, \mathrm{t}}(44)$ & $C_{\mathrm{l}, \mathrm{t}}(42)$ & $\theta(31)$ & $B_{\mathrm{M}, \mathrm{imb}}(54)$ & $C_{1, \mathrm{t}}(52)$ & $B_{\mathrm{M}, \mathrm{imb}}(42)$ & $B_{\mathrm{M}}(48)$ & $B_{\mathrm{M}, \mathrm{imb}}(26)$ \\
\hline$B_{\mathrm{M}}(47)$ & $\theta(36)$ & $c_{\mathrm{b}}(11)$ & $\varphi(16)$ & $\varphi(19)$ & $B_{M}(28)$ & $B_{\mathrm{M}}(21)$ & $B_{\mathrm{M}, \mathrm{imb}}(38)$ & $\theta / \varphi(27)$ & $T_{\mathrm{DR}}(2)$ & $B_{\mathrm{M}} / C_{\mathrm{l}, \mathrm{t}} / N_{\mathrm{M}}(10)$ \\
\hline
\end{tabular}



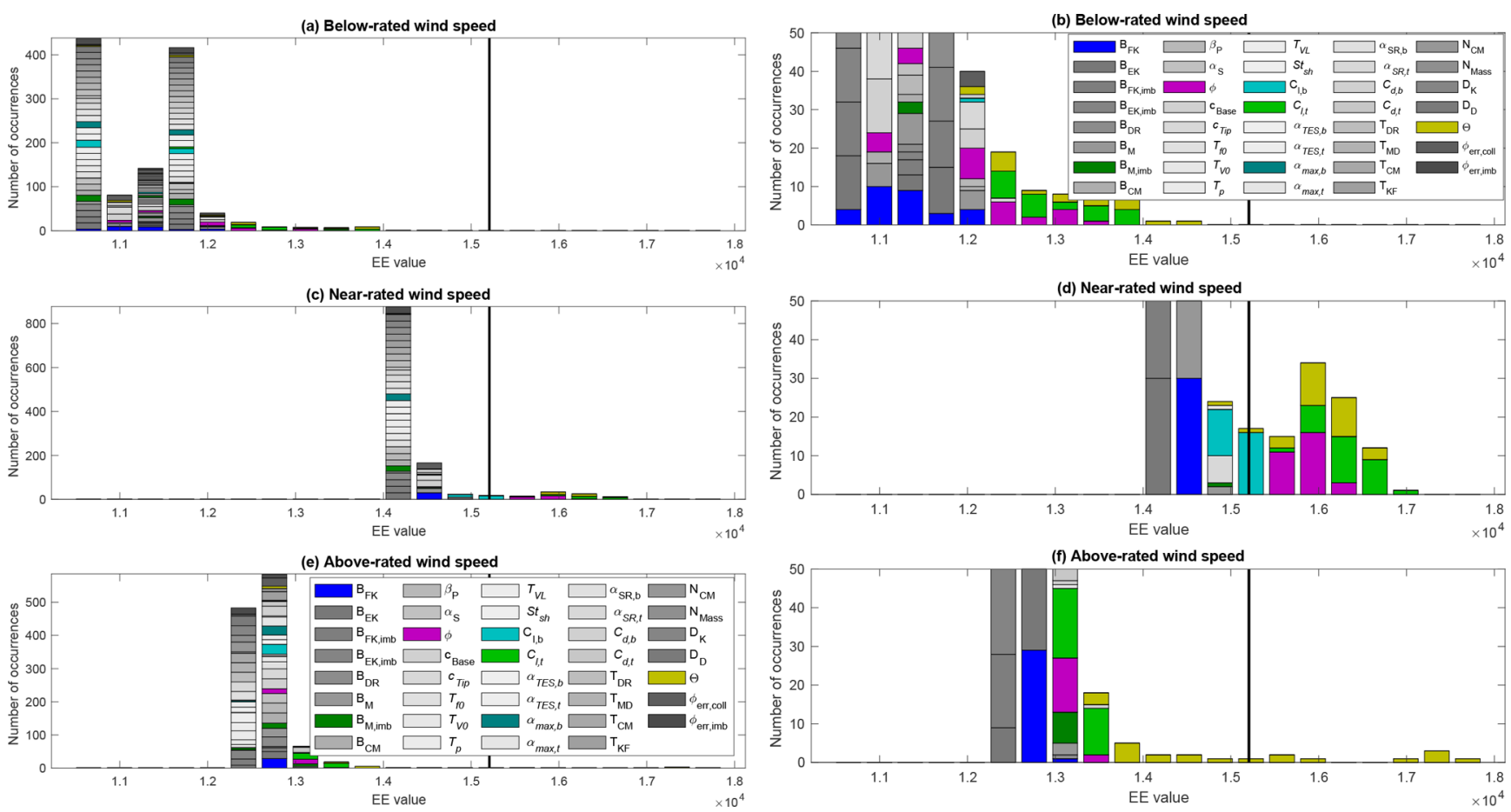

Figure 16. EE-value histograms of blade-root bending ultimate moment. Each graph shows one wind speed bin and includes all input parameters. Right column is a zoomed-in view of the left column.
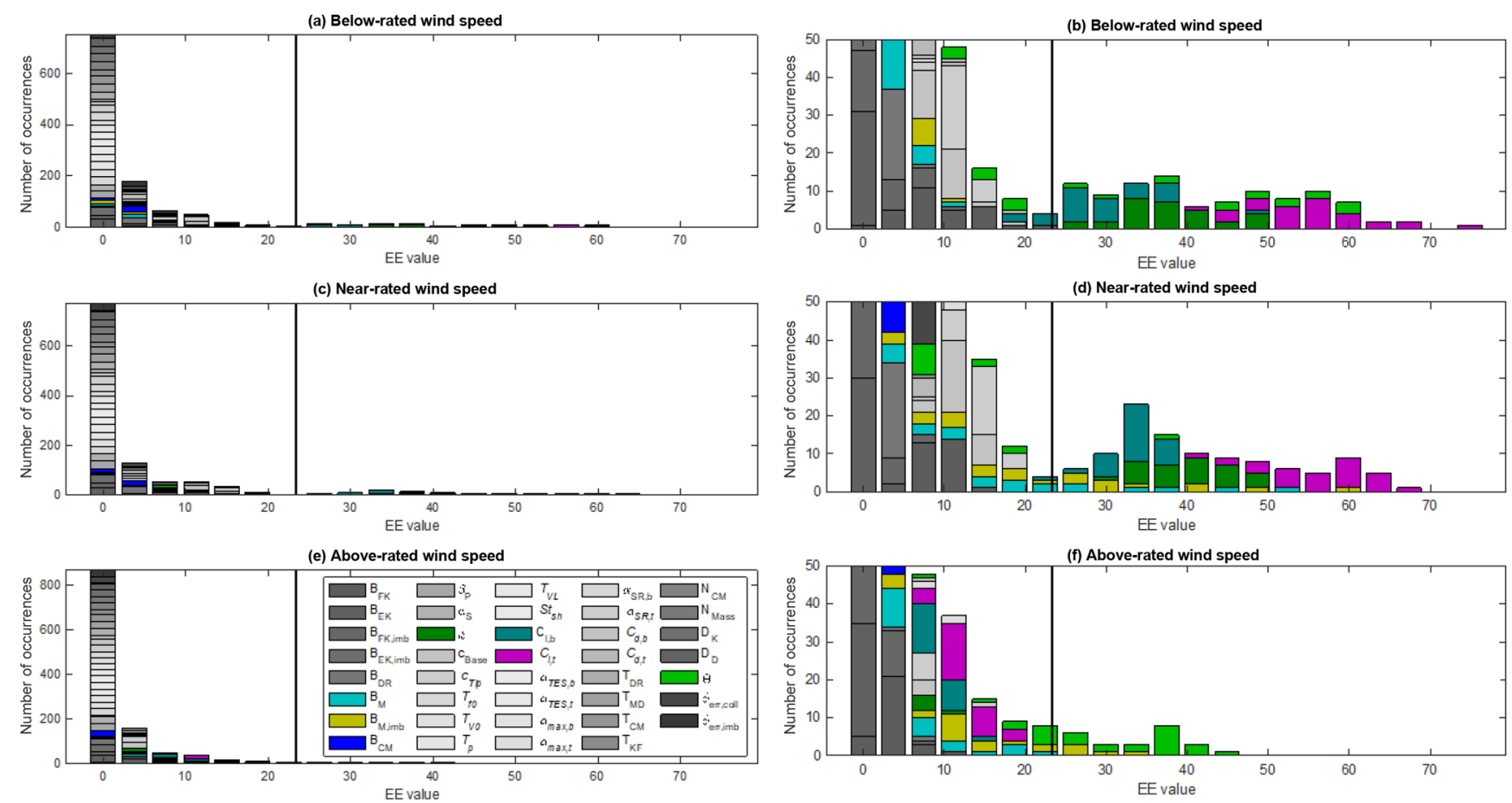

Figure 17. EE-value histograms of blade-root OoP bending fatigue moment. Each graph shows one wind speed bin and includes all input parameters. Right column is a zoomed-in view of the left column. 
(a) Blade-root bend. mom.

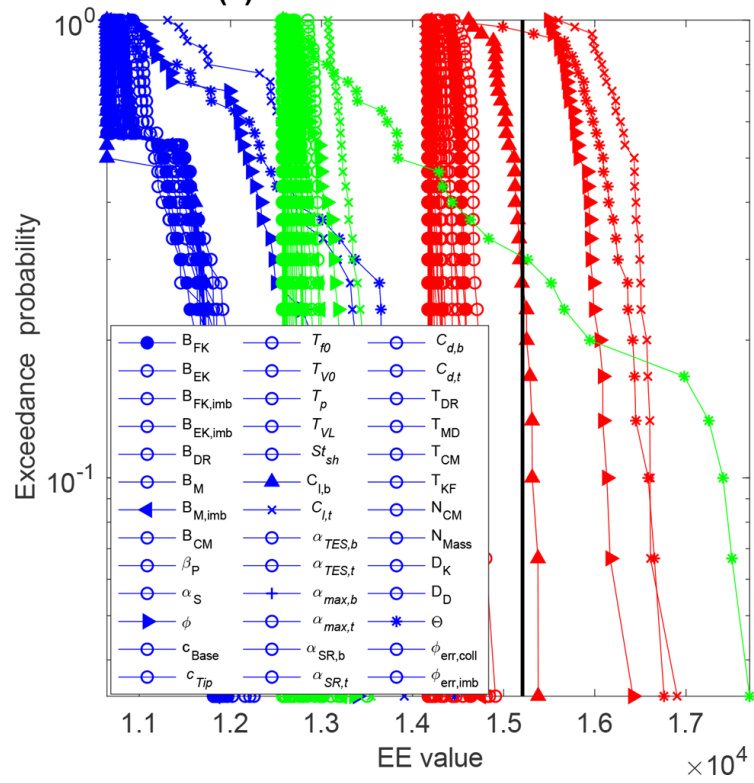

(b) Blade-root OoP bend. mom.

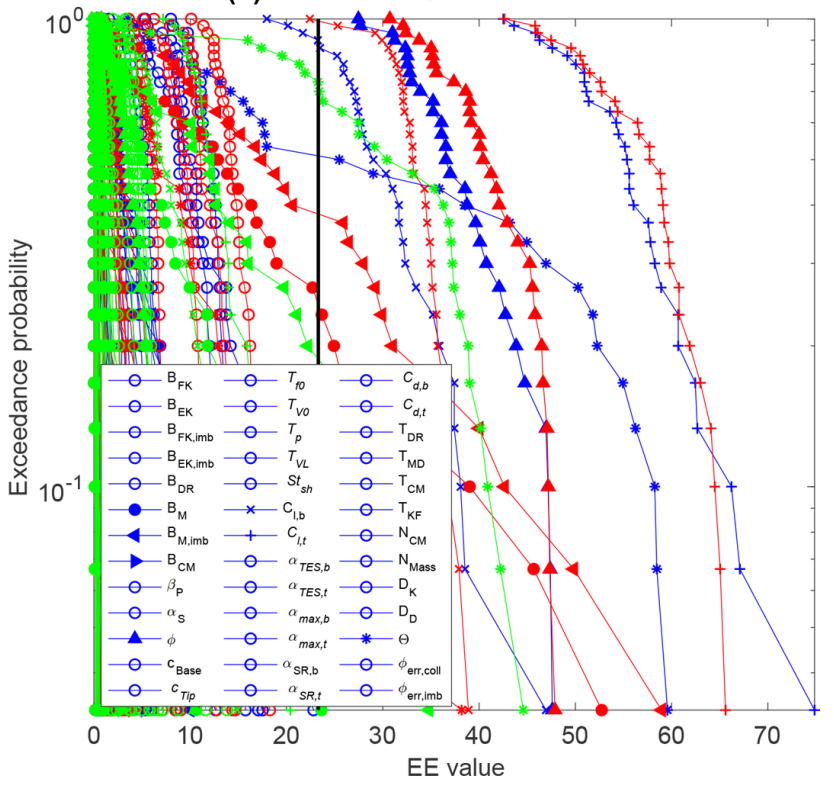

Figure 18. EE-value exceedance probability plots for the blade-root bending ultimate moment (a) and blade-root OoP bending fatigue moment (b). Each line represents a different input parameter and wind speed bin (blue is below-rated speed, red is near-rated speed, green is above-rated speed).

of inputs. However, blade mass imbalance and blade mass account for $44 \%$ of the most sensitive parameters associated with tower moment fatigue loads. Rotor torque ultimate and fatigue loads are most sensitive to perturbation of structural input parameters, especially those related to blade mass. For both ultimate and fatigue loads, electrical power is most sensitive to blade mass imbalance, blade mass factor, and yaw error. These results can be used in future sensitivity analysis work to focus on perturbation of specific input parameters based on desired turbine loads.

\section{Conclusions}

A screening analysis of the most sensitive turbulent wind and aeroelastic parameters to the resulting structural loads and power QoI was performed for the representative NREL $5 \mathrm{MW}$ wind turbine under normal operating conditions. The purpose of the study was to assess the sensitivity of different turbulent wind and turbine parameters on the resulting loads of the wind turbine. The sensitivities of the different parameters were ranked. The study did not consider specific site conditions but rather focused on understanding the most sensitive parameters across the range of possible values for a variety of sites.

To limit the number of simulations required, a screening analysis using the EE method was used instead of a more computationally intensive sensitivity analysis. The EE method is an assessment of the local sensitivity of a parameter at a given location in space through variation of only that parameter, examined over multiple points throughout the parameter hyperspace, making it a global sensitivity analysis. This work modified the general EE formula to examine the sensitivity of parameters across multiple wind speed bins. A radial version of the method was employed, using Sobol numbers as starting points, and a set delta value of $10 \%$ for the parameter variations. The most sensitive input parameters were identified using the EE value threshold.

Two independent case studies were performed. For the wind parameter case study, it was found that the loads and power are highly sensitive to the shear and turbulence levels in the $u$ direction. To a lesser extent, turbine loads are sensitive to the wind veer and the integral length scale and coherence parameters in the $u$ direction. The combinations of parameters in this study spanned the ranges of several different locations. The parameters were considered independent of one another (conditioned only on wind speed bin), which likely resulted in some nonphysical wind scenarios. However, the screening analysis has shown which parameters are most important to examine in more detail in future work.

The aeroelastic parameter case study showed that the loads and power are highly sensitive to the yaw error and the lift distribution at the outboard section of the blade. To a lesser extent, turbine loads are sensitive to blade twist distribution, lift distribution at the inboard section of the blade, and blade mass imbalance. Additionally, ultimate load EE values are typically separated by wind speed bin, whereas fatigue load EE values are more evenly distributed across wind speed bins. 
Through the implemented EE method, different combinations of input parameters have been used. When specific input parameters are shown to be sensitive to one or more turbine loads, it is possible that only certain combinations of the input parameters will result in this sensitivity. This leads to opportunities for future work to further investigate which parameter combinations lead to higher turbine sensitivity. In future work, this ranking of most sensitive parameters could be used to help establish uncertainty bars around predictions of engineering models during validation efforts and provide insight into probabilistic design methods and site-suitability analysis. Although the most sensitive ranking results may depend on the turbine size or configuration, the analysis process developed here could be applied universally to other turbines. This work could also be further expanded in future work to include load cases other than normal operation.

Data availability. While this study sought to minimize computational expense, hundreds of thousands of simulations were run to perform the analysis. The models that the work is based on are publicly available through the National Wind Technology ComputerAided Tools website (https://nwtc.nrel.gov/CAE-Tools, last access: 10 September 2019). The large amount of data produced made it impractical to save and to share publicly. The statistics presented in the plots in this paper serve as the best means to share the information developed. 
Appendix A: Mean and standard deviation of elementary effects

To identify which parameters are the most sensitive, some researchers compare the average of the EE values for the different parameters across all input starting points. Additionally, some look at the standard deviation of the EE values for a given parameter across the different starting points. This helps to identify large sensitivity variation at different points, indicating strong interaction with the values of other parameters. As commonly found in EE-related literature, EE analysis typically identifies the most sensitive parameters using a plot to pictorially show the standard deviation versus mean values of the EE values. However, it is difficult to systematically identify the most sensitive parameters using this approach.

The mean of the absolute EE value for the ultimate loads for each QoI with input parameter $i$ and bin $b$ is calculated as

$\mu_{i b}^{*}=\frac{1}{R} \sum_{r=1}^{R}\left|\mathrm{EE}_{i b}^{r}\right|$,

where $R$ is the number of points at which the EE value is calculated. The standard deviation of the EE is then calculated as

$\sigma \mu_{i b}=\sqrt{\frac{1}{(R-1)} \sum_{r=1}^{R}\left(\mathrm{EE}_{i b}^{r}-{ }_{i b}\right)^{2}}$

and $\mu_{i b}$ is defined as

$\mu_{i b}=\frac{1}{R} \sum_{r=1}^{R} \mathrm{EE}_{i b}^{r}$.

This is shown in Figs. A1 and A2 for the blade-root bending ultimate moment and the blade-root bending OoP fatigue moment metrics for both the wind parameter and turbine parameter case studies, respectively. Shown in Fig. A1 is the large sensitivity of shear in the lowest wind speed bin and the large sensitivity of the $u$ turbulence across all wind speed bins. Shown in Fig. A2 is the large sensitivity of yaw error in the below-rated wind speed bin and the large sensitivity of the lift distribution at the outboard section of the blade in the below- and near-rated wind speed bins. 

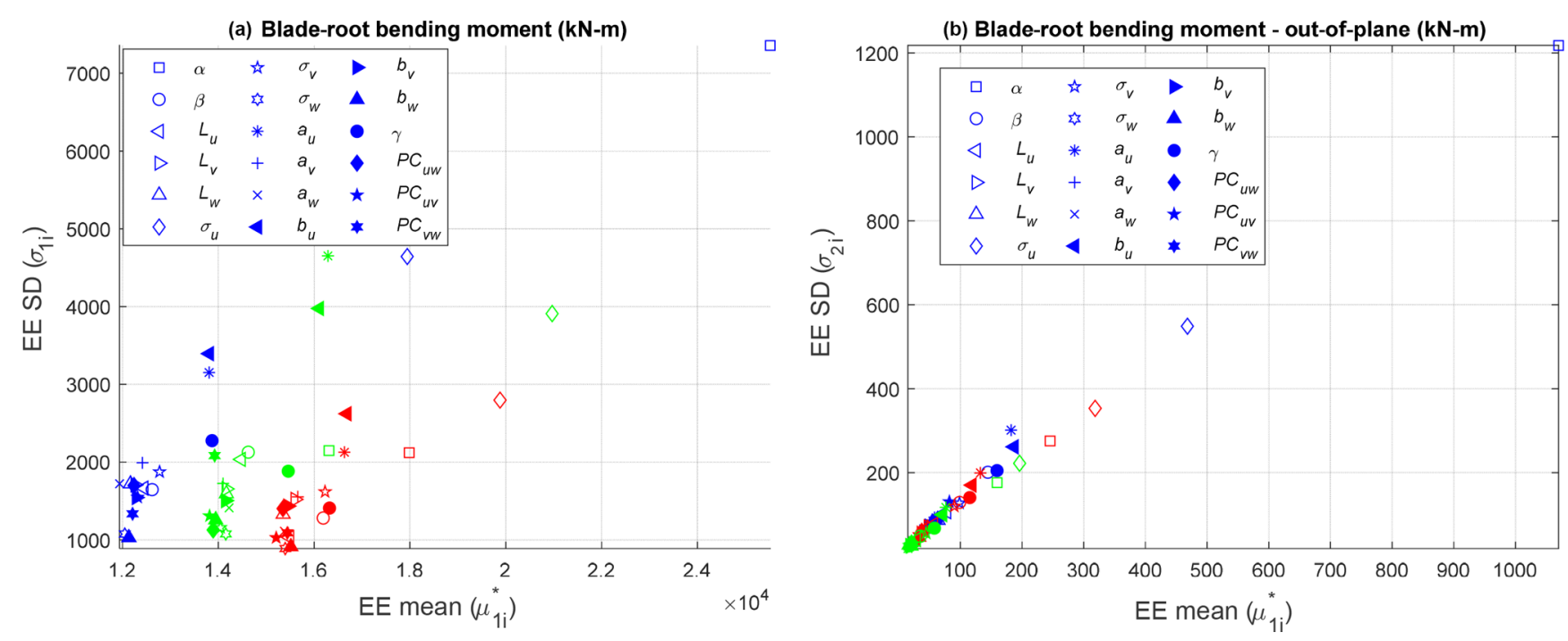

Figure A1. EE standard deviation versus EE mean for blade-root bending moment ultimate load (a) and blade-root Oop bending moment fatigue load (b) at all wind speed bins (blue is below-rated speed, red is near-rated speed, green is above-rated speed).
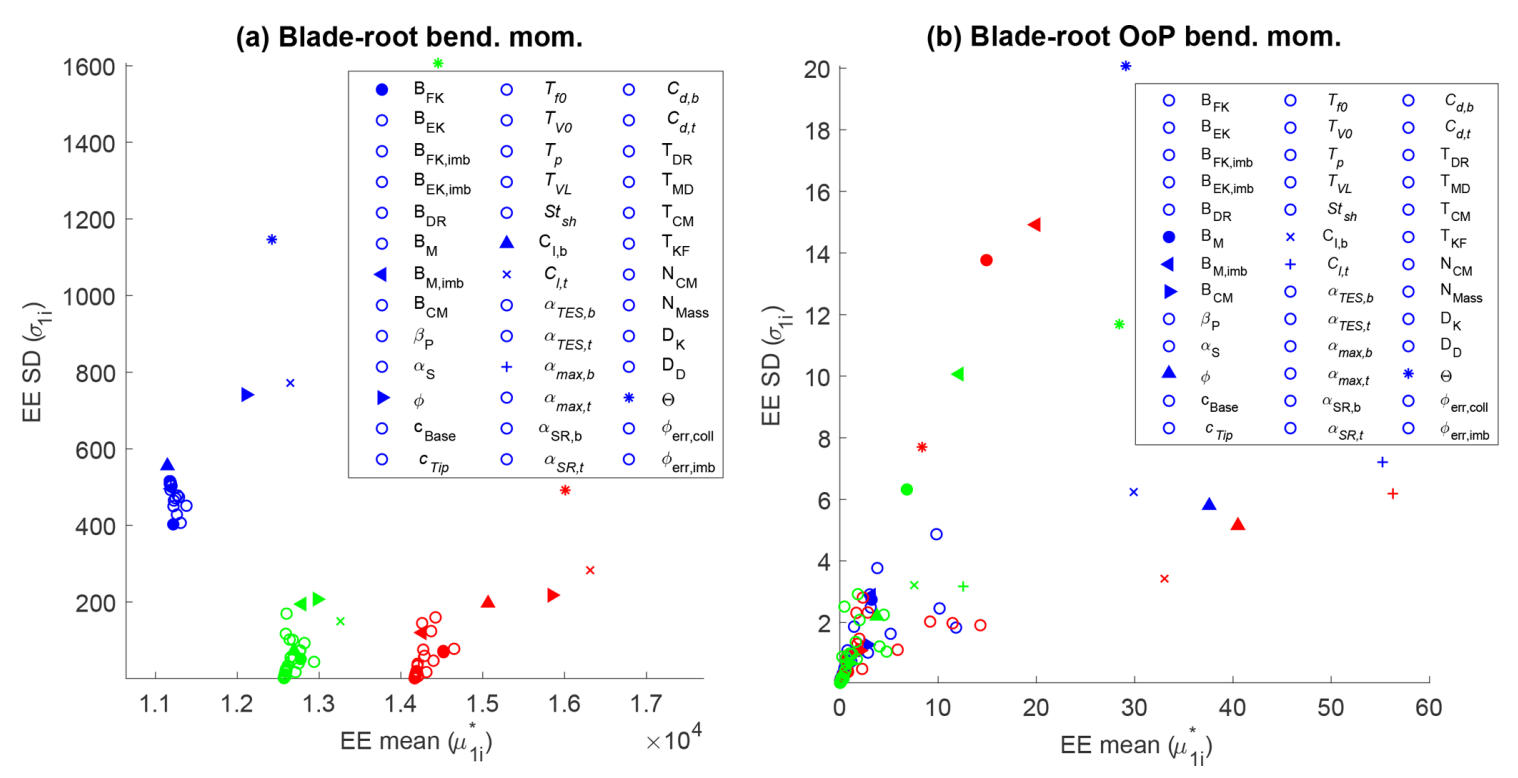

Figure A2. EE standard deviation versus EE mean for blade-root bending moment ultimate load (a) and blade-root Oop bending moment fatigue load (b) at all wind speed bins (blue is below-rated speed, red is near-rated speed, green is above-rated speed). 
Appendix B: Exceedance probability plots of elementary effects
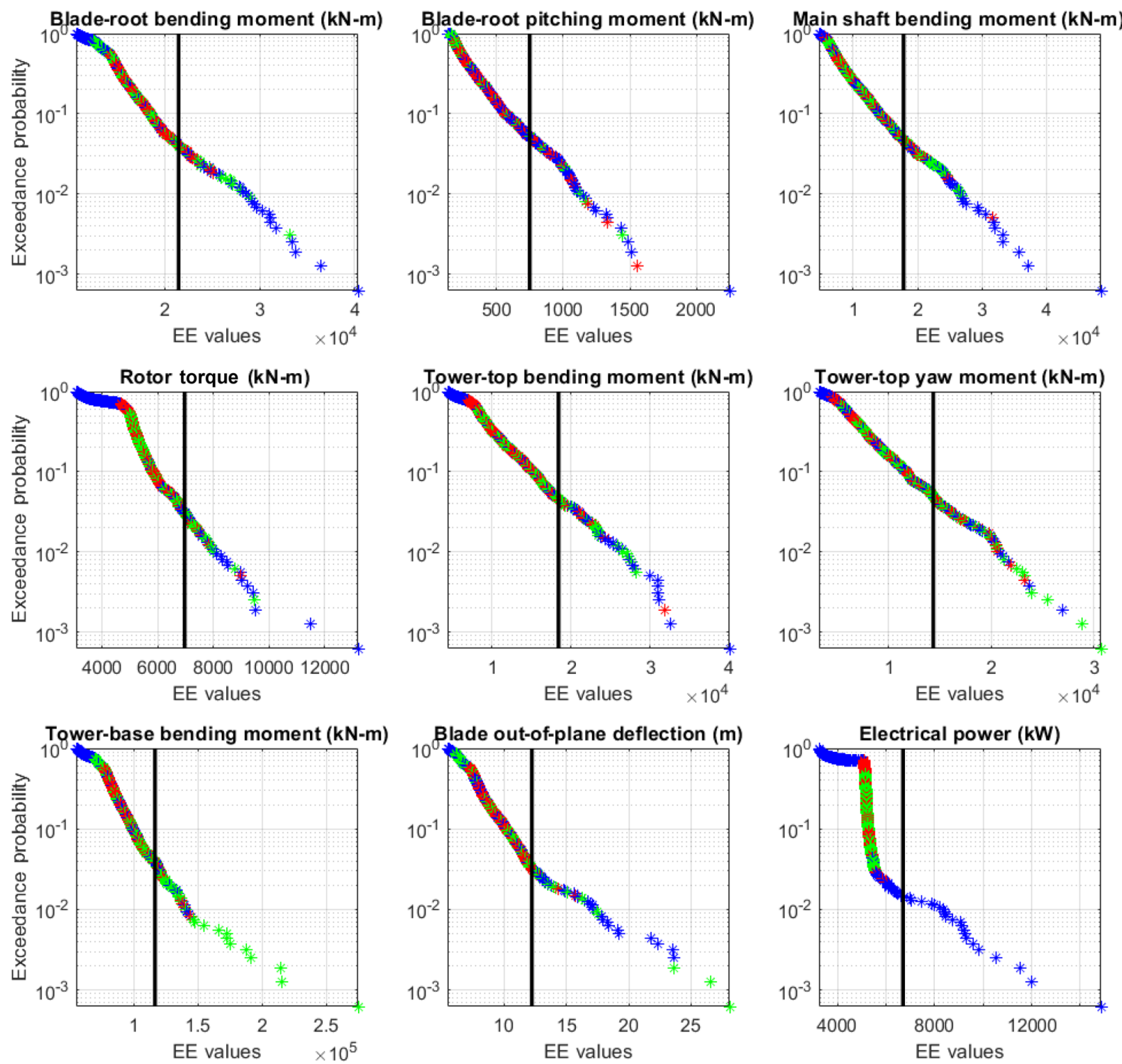

Figure B1. Exceedance probability plot of ultimate load EE values for each of the wind-inflow parameter QoIs across all wind speed bins, input parameters, and simulation points. Black line represents the defined threshold by which outliers are counted for each QoI. Color indicates wind speed bin (blue is below-rated speed, red is near-rated speed, green is above-rated speed). 
Blade-root IP bend. mom.

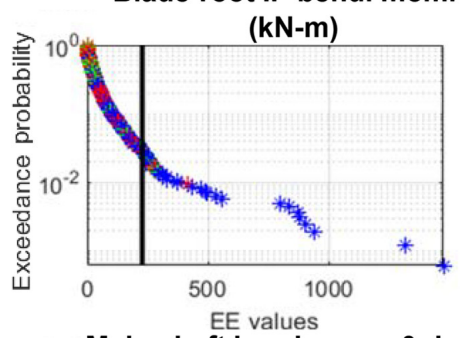

Main shaft bend. mom. 0 deg

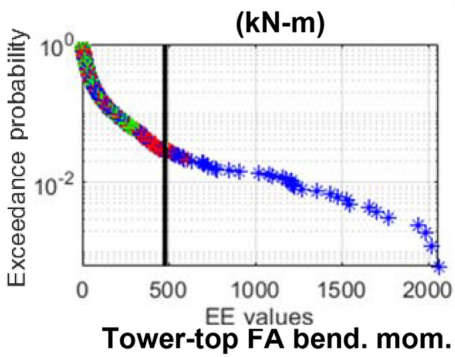

(kN-m)

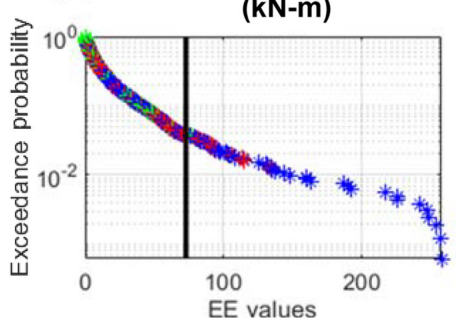

Tower-base FA bend. mom.

(kN-m)

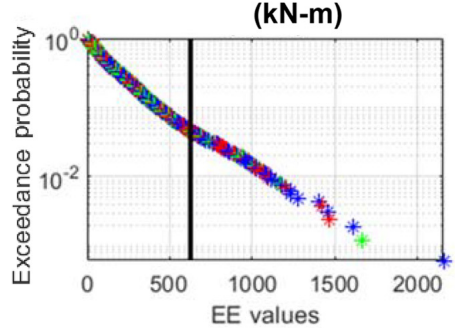

Blade-root OoP bend. mom. (kN-m)

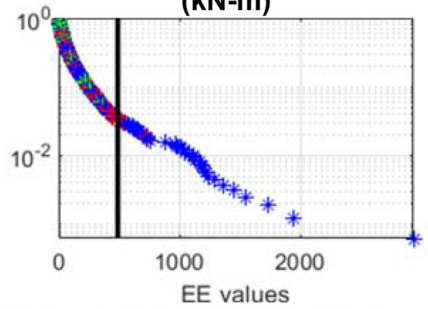

end. mom. 90 deg

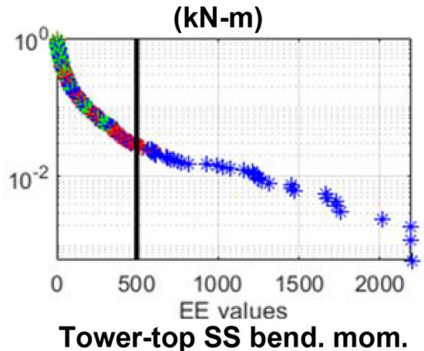

(kN-m)

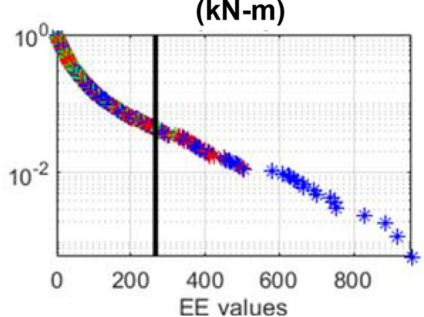

Tower-base SS bend. mom.

$(\mathrm{kN}-\mathrm{m})$

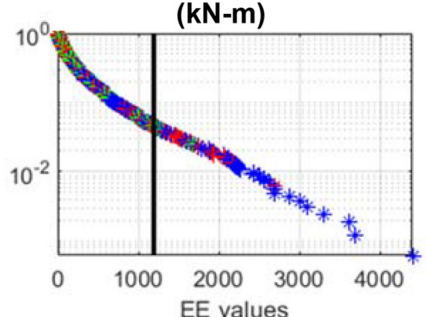

Blade-root pitch. mom. it (kN-m)

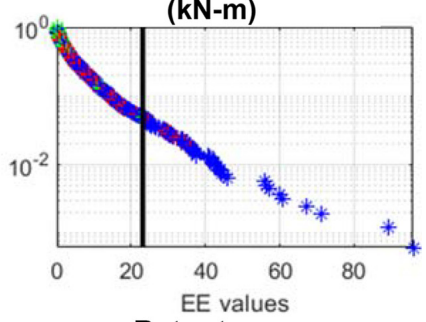

Rotor torque

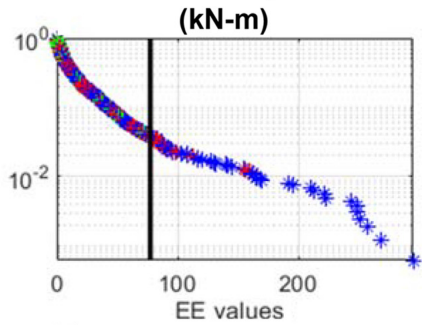

Tower-top yaw mom.

$(\mathrm{kN}-\mathrm{m})$

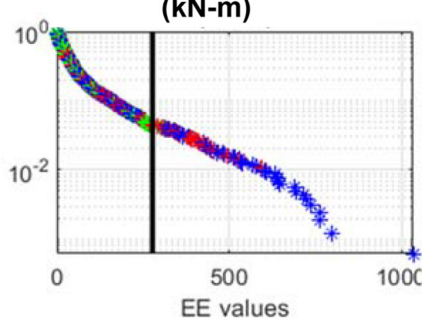

Electrical power $(\mathrm{kW})$

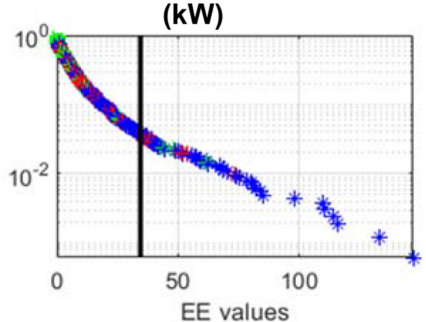

Figure B2. Exceedance probability plot of fatigue load EE values for each of the wind-inflow parameters across all wind speed bins, input parameters, and simulation points. Black line represents the defined threshold by which outliers are counted for each QoI. Color indicates wind speed bin (blue is below-rated speed, red is near-rated speed, green is above-rated speed). 
Blade-root bend. mom. (kN-m)

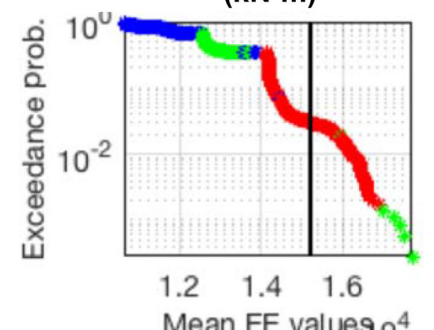

Mean EE values $0^{4}$

Rotor torque

(kN-m)

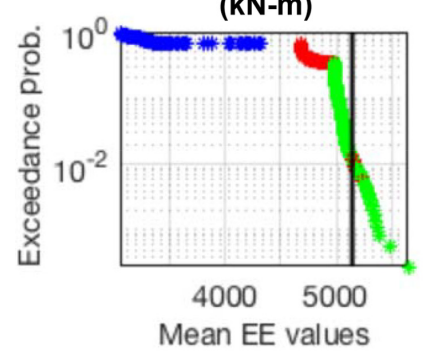

Tower-base bend. mom.

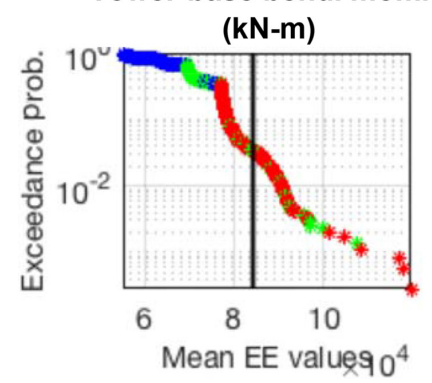

Blade-root pitch. mom. (kN-m)

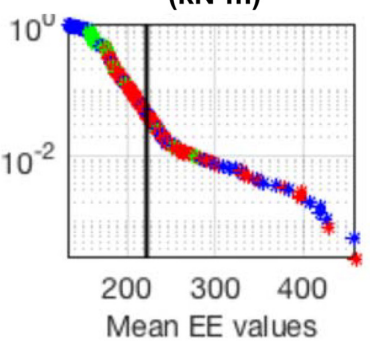

Tower-top bend. mom. (kN-m)

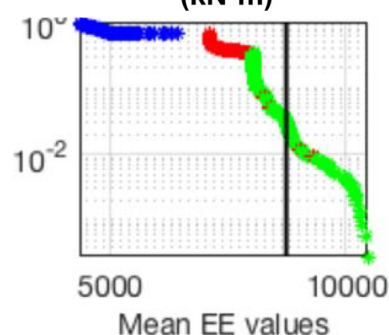

Blade OoP def.

(m)

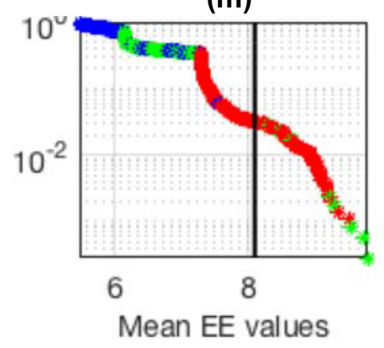

Main shaft bend. mom.

(kN-m)

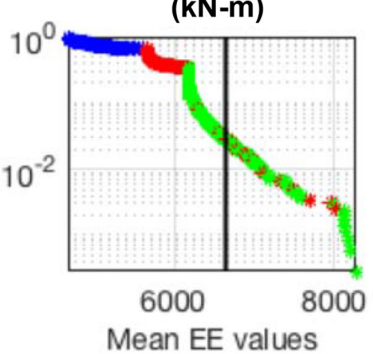

Tower-top yaw mom.

(kN-m)

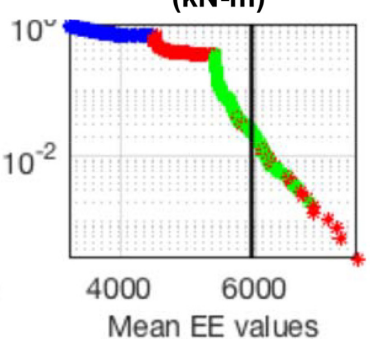

Electrical power (kW)

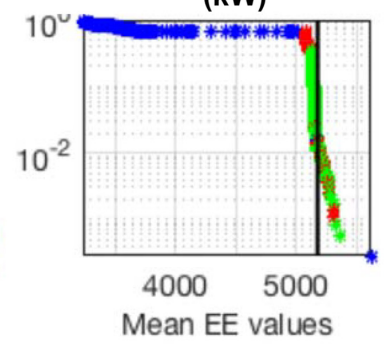

Figure B3. EE-value exceedance probability plots of ultimate loads for aeroelastic turbine parameters, across all wind speed bins, input parameters, and simulations points for all QoIs. The black line represents the defined threshold by which outliers are counted for each QoI. Color indicates wind speed bin (blue is below-rated speed, red is near-rated speed, green is above-rated speed). 

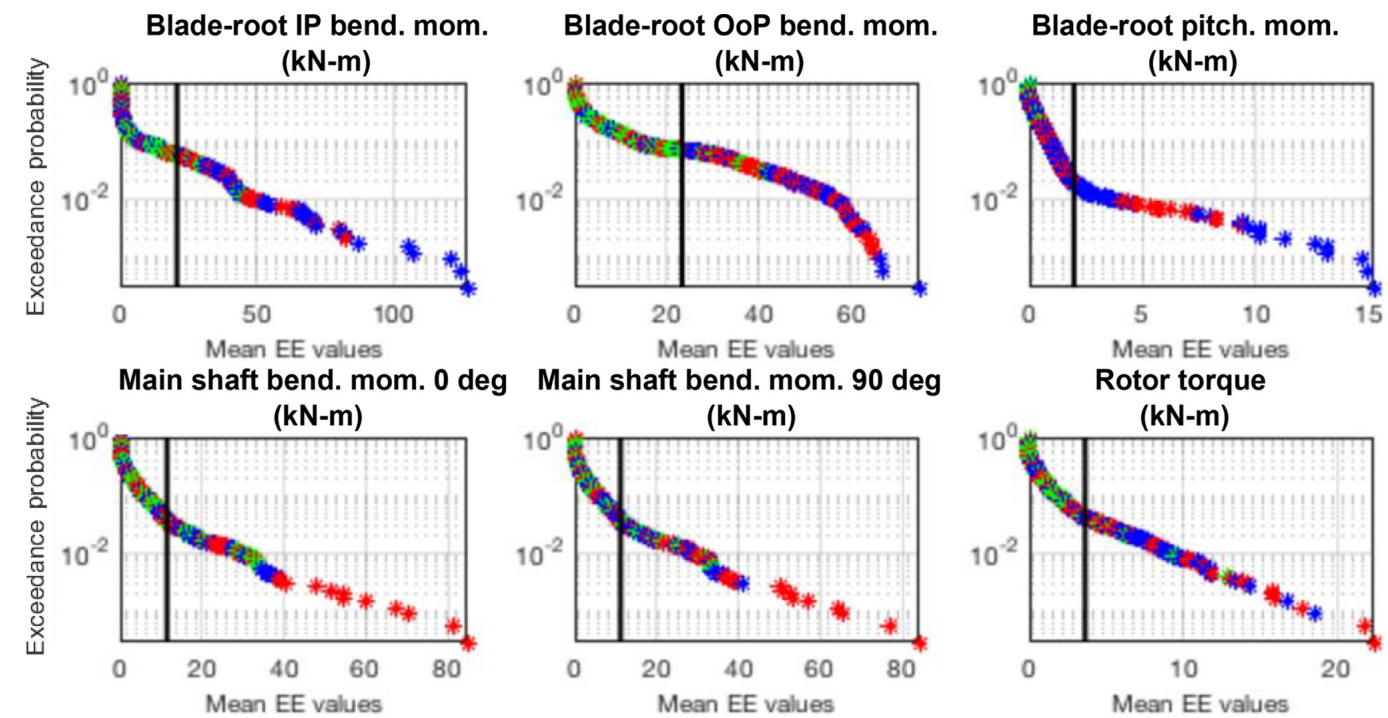

Main shaft bend. mom. 90 deg

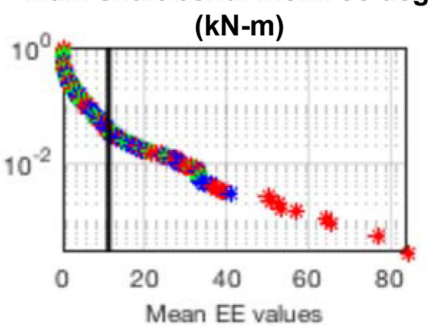

Rotor torque

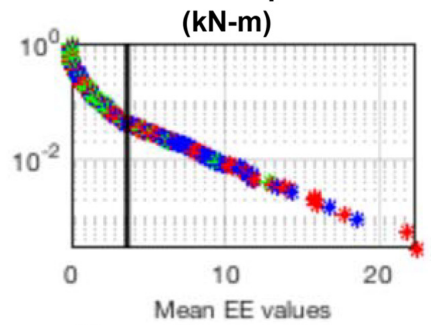

Tower-top FA bend. mom.
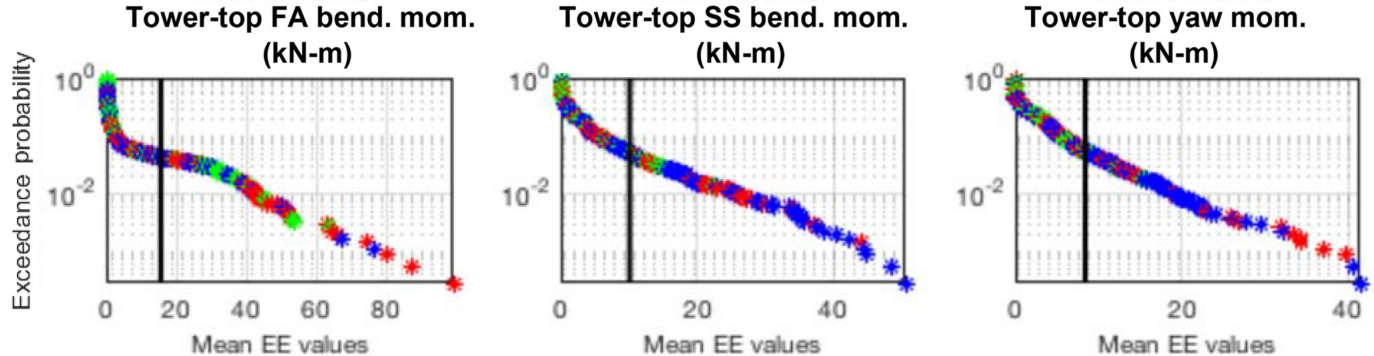

Tower-base FA bend. mom.
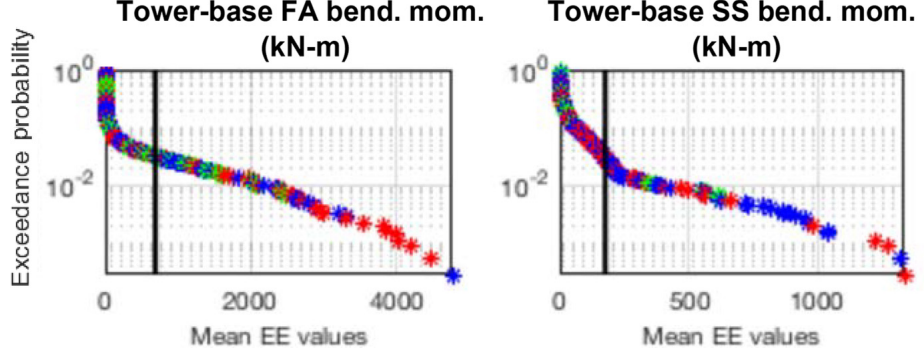

Mean EE values

Electrical power

$(\mathrm{kW})$

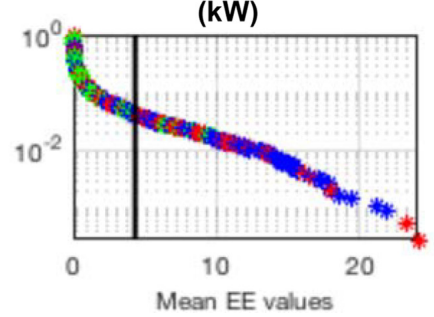

Figure B4. EE-value exceedance probability plots of fatigue loads of aeroelastic turbine parameters across all wind speed bins, input parameters, and simulations points for all QoIs. The black line represents the defined threshold by which outliers are counted for each QoI. Color indicates wind speed bin (blue is below-rated speed, red is near-rated speed, green is above-rated speed). 
Author contributions. JJ provided the conceptualization and supervision for this project. ANR developed the EE methodology approach used within both parameter studies. KS led the investigation of the wind turbine property sensitivity study, and LS led the investigation of the wind characteristics study. ANR and KS prepared the article, with support from JJ and LS.

Competing interests. The authors declare that they have no conflict of interest.

Disclaimer. The views expressed in the article do not necessarily represent the views of the DOE or the U.S. Government.

Acknowledgements. This work was authored by Alliance for Sustainable Energy, LLC, the manager and operator of the National Renewable Energy Laboratory for the U.S. Department of Energy (DOE) under contract no. DE-AC36-08GO28308.

Financial support. This research has been supported by the U.S. Department of Energy, National Renewable Energy Laboratory (contract no. DE-AC36-08GO28308). Funding was provided by the Department of Energy Office of Energy Efficiency and Renewable Energy, Wind Energy Technologies Office.

Review statement. This paper was edited by Michael Muskulus and reviewed by Imad Abdallah and two anonymous referees.

\section{References}

Abdallah, I.: Assessment of extreme design loads for modern wind turbines using the probabilistic approach, PhD Disseration, DTU Wind Energy, Denmark, No. 0048(EN), 2015.

Abdallah, I., Natarajan, A., and Sorensen, J.: Impact of Uncertainty in Airfoil Characteristics on Wind Turbine Extreme Loads, Renew. Energ., 75, 283-300, https://doi.org/10.1016/j.renene.2014.10.009, 2015.

Berg, J., Mann, J., and Patten, E. G.: Lidar-Observed Stress Vectors and Veer in the Atmospheric Boundary Layer, J. Atmos. Ocean. Tech., 30, 1961-1969, 2013.

Bulaevskaya, V., Wharton, S., Clifton, A., Qualley, G., and Miller, W. O. Wind power curve modeling in complex terrain using statistical models, J. Renew. Sustain. Energ., 7, 013103, doi:10.1063/1.4904430, 2015.

Campolongo, F., Cariboni, J., and Saltelli, A.: An Effective Screening Design for Sensitivity Analysis of Large Models, Environ. Model. Softw., 22, 1509-1518, 2007.

Campolongo, F., Saltelli, A., and Cariboni, J.: From Screening to Quantitative Sensitivity Analysis - A Unified Approach, Comput. Phys. Commun., 182, 978-988, 2011.

Clifton, A.: 135-m Meteorological Towers at the NWTC: Instrumentation, Data Acquisition and Processing, Draft, available at: https://wind.nrel.gov/MetData/Publications/ (last access: 5 August 2019), 2014.
Damiani, R. R., Hayman, G. J., and Jonkman, J.: Development and Validation of a New Unsteady Airfoil Aerodynamics Model Within AeroDyn, AIAA SciTech Forum, San Diego, CA, 1-21, https://doi.org/10.2514/6.2016-1007, 2016.

Dimitrov, N., Natarajan, A., and Kelly, M.: Model of Wind Shear Conditional on Turbulence and Its Impact on Wind Turbine Loads, Wind Energy, 18, 1917-1931, 2015.

Dimitrov, N., Kelly, M. C., Vignaroli, A., and Berg, J.: From wind to loads: wind turbine site-specific load estimation with surrogate models trained on high-fidelity load databases, Wind Energ. Sci., 3, 767-790, https://doi.org/10.5194/wes-3-767-2018, 2018.

Downey, R.: Uncertainty in Wind Turbine Life Equivalent Load due to Variation of Site Conditions, MSc Thesis Project, DTU Wind Energy, Denmark, 2006.

Eggers, A., Digumarthi, R., and Chaney, K.: Wind Shear and Turbulence Effects on Rotor Fatigue and Loads Control, T. ASME, 125, 402-409, 2003.

Ehrmann, R. S., Wilcox, B., White, E. B., and Maniaci, D. C.: Effect of Surface Roughness on Wind Turbine Performance, Tech. Rep. SAND2017-10669, Sandia National Laboratory, Albuquerque, NM, October 2017.

Ernst, B., and Seume, J.: Investigation of Site-Specific Wind Field Parameters and Their Effect on Loads of Offshore Wind Turbines, Energies, 5, 3835-3855, 2012.

Francos, A., Elorza, F., Bouraoui, F., Bidoglio, G., and Galbiati, L.: Sensitivity Analysis of Distributed Environmental Simulation Models: Understanding the Model Behavior in Hydrological Studies at the Catchment Scale, Reliab. Eng. Syst. Safe., 79, 205-218, 2003.

Gan, Y., Duan, Q., Gong, W., Tong, C., Sun, Y., Chu, W., Ye, A., Miao, C., and Di, Z.: A Comprehensive Evaluation of Various Sensitivity Analysis Methods: A Case Study with a Hydrological Model, Environ. Model. Softw., 51, 269-285, 2014.

Hayman, G. and Buhl, J.: MLife User's Guide for Version 1.00, NREL Technical Report, 2012.

Holierhoek, J. G., Korterink, H., van de Pieterman, Braam, H., Rademakers, L. W. M. M., Lekou, D. J., and Hecquet, T.: PROTEST: Recommended Practices for Measuring in Situ the Loads on Drive Train, Pitch System, and Yaw System, ECN, PROTEST project deliverable D6, D7, D8, 2010.

Holtslag, M., Bierbooms, W., and Bussel, G.: Wind Turbine Fatigue Loads as a Function of Atmospheric Conditions, Wind Energy, 19, 1917-1932, 2016.

Huang, Y. and Pierson, D.: Identifying Parameter Sensitivity in Water Quality Model of a Reservoir, Water Qual. Res. J. Can., 47, 51-462, 2012.

IEC: IEC 61400-1 Ed. 3, Wind Turbines - Part 1: Design Requirements, 2005

IEC: IEC 61400-5 Ed. 3, Wind Turbines - Part 5: Rotor Blades Wind Turbines, 2010.

Jansen, M.: Analysis of Variance Designs for Model Output, Comput. Phys. Commun., 117, 35-43, 1999.

Jonkman, B.: TurbSim User's Guide v1.50, NREL Technical Report, NREL/TP-500-46198, 2009.

Jonkman, J., Butterfield, S., Musial, W., and Scott, G.: Definition of a 5 MW Reference Wind Turbine for Offshore System Development, NREL Technical Report, NREL/TP-500-38060, February 2009. 
Kalverla, P., Steeeveld, G., Ronda, R., and Holtslag, A. A. M.: An Observational Climatology of Anomalous Wind Events at Offshore Meteomast Ijmuiden (North Sea), J. Wind Eng. Ind. Aerod., 165, 86-99, 2017.

Kelley, N.: Turbulence-Turbine Interaction: The Bases for the Development of the TurbSim Stochastic Simulator, NREL Technical Report, NREL/TP-5000-52353, 2011.

Kelly, M., Larsen, G., Dimitrov, N., and Natarajan, A.: Probabilistic Meteorological Characterization for Turbine Loads, The Science of Making Torque from Wind 2014 (TORQUE 2014), J. Phys. Conf. Ser., 524, 012076, https://doi.org/10.1088/17426596/524/1/012076, 2014.

Koukoura, C.: Validated Loads Prediction Models for Offshore Wind Turbines for Enhanced Component Reliability, PhD Dissertation, DTU Wind Energy, Denmark, No. 0026 (EN), 2014.

Lindelöw-Marsden, P.: Uncertainties in Wind Assessment with LIDAR, Risø-R-1681UpWind Deliverable D1, Risø National Laboratory for Sustainable Energy, DTU, Denmark, January 2009.

Loeven, G. J. A. and Bijl, H.: Airfoil Analysis with Uncertain Geometry Using the Probabilistic Collection Method, AIAA Structures, Structural Dynamics, and Materials Conference, Schaumburg, IL, 7-10 April, 2008.

Madsen, H. A., Bak, C., Paulsen, U. S., Gaunaa, M., Fuglsang, P., Romblad, J., Olesen, N. A., Enevoldsen, P., Laursen, J., and Jensen, L.: The DAN-AERO MW Experiments Final Report, Tech. Rep. Ris $\varnothing-\mathrm{R}-1726$ (EN), Ris $\varnothing$ DTU, Roskilde, Denmark, September 2010.

Martin, R., Lazakis, I., Barbouci, S., and Johanning, L.: Sensitivity Analysis of Offshore Wind Farm Operation and Maintenance Cost and Availability, Renew. Energ., 85, 1226-1236, 2016.

Matthaus, D., Bortolotti, P., Loganathan, J., and Bottasso, C. L.: A Study of the Propagation of Aero and Wind Uncertainties and their Effect on the Dynamic Loads of a Wind Turbine, AIAA SciTech Forum, Grapevine, TX, 9-13 January, 2017.

Moriarty, P., Holley, W., and Butterfield, S.: Effect of Turbulence Variation on Extreme Loads Prediction of Wind Turbines, J. Sol. Energ.-T. ASME, 124, 387-395, 2002.

Moroz, E.: Time to Upgrade the Wind Turbine Suitability Process, Presentation at AWEA WindPower, Anaheim, CA, 22-25 May, 2017.

Nelson, L. D., Manuel, L., Sutherland, H. J., and Veers, P. S.: Statistical Analysis of Wind Turbine Inflow and Structural Response Data from the LIST Program, J. Sol. Energ.-T. ASME, 125, 541550, 2003.

OpenFAST: OpenFAST Documentation, available at: http:// openfast.readthedocs.io/en/master (last access: 5 August 2019), November 2017.

Park, J., Manuel, L., and Basu, S.: Toward Isolation of Salient Features in Stable Boundary Layer Wind Fields that Influence Loads on Wind Turbines, Energies, 8, 2977-3012, 2015.

Petrone, G., de Nicola, C., Quagliarella, D., Witeveen, J., and Iaccarino, G.: Wind Turbine Performance Analysis Under Uncertainty, AIAA Aerospace Sciences Meeting, Orlando, FL, 4-7 January, 2011.

Quick, J., Annoni, J., King, R., Dykes, K., Flemming, P., and Ning, A.: Optimization Under Uncertainty for Wake Steering Strategies, Wake Conference, Visby, Sweden, 30 May-1 June 2017, p. 854, 2017.
Rinker, J.: Calculating the Sensitivity of Wind Turbine Loads to Wind Inputs Using Response Surfaces, The Science of Making Torque from Wind (TORQUE 2016), J. Phys. Conf. Ser., 753, 032057, https://doi.org/10.1088/1742-6596/753/3/032057, 2016.

Robertson, A., Sethuraman, L., Jonkman, J., and Quick, J.: Assessment of Wind Parameter Sensitivity on Ultimate and Fatigue Wind Turbine Loads, Presented at the American Institute of Aeronautics and Astronautics SciTech Forum, Orlando, Florida, 8-12 January, 2018.

Saint-Geours, N. and Lilburne, L.: Comparison of Three Spatial Sensitivity Analysis Techniques, Accuracy 2010 Symposium, Leicester, UK, 20-23 July, 2010.

Saltelli, A., Ratto, M., Andres, T., Campolongo, F., Cariboni, J., Gatelli, D., Saisana, M., and Tarantola, S.: Global Sensitivity Analysis, The Primer, John Wiley \& Sons Ltd., 2008.

Santos, R. and van Dam, J.: Mechanical Loads Test Report for the U.S. Department of Energy 1.5-Megawatt Wind Turbine, NREL Technical Report, NREL/TP-5000-63679, 2015.

Saranyasoontorn, K. and Manuel, L.: On the Study of Uncertainty in Inflow Turbulence Model Parameters in Wind Turbine Applications, 44th AIAA Aerospace Sciences Meeting and Exhibit, Reno, Nevada, 9-12 January 2006.

Sarayansoontorn, K. and Manuel, L.: On the Propagation of Uncertainty in Inflow Turbulence to Wind Turbine Loads, J. Wind Eng. Ind. Aerod., 96, 508-523, 2008.

Saranyasontoorn, K., Manuel, L., and Veers, P. S.: A Comparison of Standard Coherence Models for Inflow Turbulence with Estimates from Field Measurements, J. Sol. Energ.-T. ASME, 126, 1069-1082, 2004.

Sathe, A., Mann, J., Barlas, T., Bierbooms, W. A. A. M., and van Bussel, G. J. W.: Influence of atmospheric stability on wind turbine loads, Wind Energy, 16, 1013-1032, 2012.

Simms, D., Schreck, S., Hand, M., and Fingersh, L. J.: NREL Unsteady Aerodynamics Experiment in the NASA-Ames Wind Tunnel: A Comparison of Predictions to Measurements, NREL Technical Report, NREL/TP-500-29494, National Renewable Energy Laboratory, Golden, CO, June 2001.

Sohier, H., Piet-Lahanier, H., and Farges, J.: Analysis and Optimization of an Air-Launch-to-Orbit Separation, Acta Astronaut., 108, 18-29, 2015.

Solari, G.: Turbulence Modelling for Gust Loading, J. Struct. Eng.ASCE, 113, 1550-1569, 1987.

Solari, G. and Piccardo, G.: Probabilistic 3-D Turbulence Modeling for Gust Buffeting of Structures, Probabilist. Eng. Mech., 16, 7386, 2001.

Sutherland, H.: Analysis of the Structural and Inflow Data from the LIST Turbine, Sandia National Laboratories Report, SAND2002-1838J, 2002.

Teunissen, H.: Characteristics of the Mean Wind and Turbulence in the Planetary Boundary Layer, UTIAS 32, Institute for Aerospace Studies, University of Toronto, 1970.

Wagner, R., Courtney, M., and Larsen, T.: Simulation of Shear and Turbulence Impact on Wind Turbine Performance, Ris $\emptyset$-RReport 1722, DTU, Denmark, January 2010.

Walter, K., Weiss, C., Swift, A., Chapman, J., and Kelley, N. D.: Speed and Direction Shear in the Stable Nocturnal Boundary Layer, J. Sol. Energ.-T. ASME, 131, 011013, https://doi.org/10.1115/1.3035818, 2009. 
Wharton, S., Newman, J. F., Qualley, G., and Miller, W. O.: Measuring Turbine Inflow with Vertically-Profiling Lidar in Complex Terrain, J. Wind Eng. Ind. Aerodyn., 142, 217-231, 2015.

Witcher, D.: Uncertainty Quantification Techniques in Wind Turbine Design, Presentation, Systems Engineering Workshop 2017, Roskilde, Denmark, 13 September, 2017.
Ziegler, L. and Muskulus, M.: Fatigue Reassessment for Lifetime Extension of Offshore Wind Monopile Substructures, The Science of Making Torque from Wind (TORQUE 2016), J. Phys. Conf. Ser., 753, 092010, https://doi.org/10.1088/17426596/753/9/092010, 2016 